\title{
Las vasijas de Necrópolis, península de Paracas (costa sur, Perú): ENSAYO DE ANÁLISIS DE SU PRODUCCIÓN, SU DISTRIBUCIÓN Y SU DEPÓSITO EN CONTEXTOS FUNERARIOS
}

\author{
Vanessa Tinteroff ${ }^{\mathrm{a}}$
}

\begin{abstract}
Resumen
Alrededor de 550 vasijas fueron exhumadas por Julio César Tello y su equipo del cementerio de Necrópolis, peninsula de Paracas, Perú, entre 1927 y 1930. Habian sido depositadas al lado, generalmente norte, de 250 de los 429 fardos funerarios, solas o en conjunto de dos o tres, a veces envueltas en un tejido. Por comparaciones con materiales cerámicos procedentes de los valles de Chincha, Pisco, Ica y Nazca, esas vasijas fueron atribuidas en el pasado, y de manera indiferenciada, a las tradiciones alfareras Topará (Jahuay y Chongos), Paracas Tardio (Ocucaje 10) y Nasca Inicial (Nasca 1). Sin embargo, esa colección de cerámica es ampliamente desconocida y nunca fue estudiada en su totalidad, o parcialmente, según una metodología adecuada que integre su contexto arqueológico, su análisis y su clasificación tecnológicamorfológica. Tal estudio, del cual se propone en este ensayo los primeros resultados, ofrece una oportunidad unica de determinar el rol de los recipientes de cerámica en los rituales funerarios y las relaciones existentes entre las poblaciones Paracas, Nasca y Topará entre 200 a.C. y 200 d.C., a partir de la determinación de las producciones alfareras, de su procedencia y de sus redes de difusión.
\end{abstract}

Palabras clave: Paracas, Necrópolis de Wari Kayan, análisis de cerámica, alfares, arqueología mortuoria

\section{Abstract \\ CERAMICS FROM NECRÓPOLIS, PARACAS PENINSULA (SOUTH COAST, PERÚ): ESSAY OF ANALYSIS OF THEIR PRODUCTION, DISTRIBUTION AND DEPOSIT IN FUNERAL CONTEXT}

Approximately 550 vessels were recovered by Julio César Tello and his team from the Paracas Necrópolis cemetery on the Paracas peninsula, Perú, between 1927 and 1930. Each vessel had been placed adjacent to 250 of the 429 funerary bundles, generally to the north, either alone or in a group of two or three, sometimes wrapped in a cloth. Based on comparisons with ceramics from the valleys of Chincha, Pisco, Ica and Nazca, these vessels have been attributed, without differentiating them, to the Topara (Jahuay and Chongos), late Paracas (Ocucaje 10) and initial Nasca (Nasca 1) ceramic traditions. However, this ceramic assemblage is largely undocumented and has not previously been studied, in its entirety or in part, using systematic methods that include information on the archaeological context, the analytic process and a technological and morphological classification. This essay presents initial results of this type of study, offering a unique opportunity to determine the role of ceramic receptacles in the funerary rites and social relationships among Paracas, Nasca y Topará populations between 200 BCE and 200 CE, based on determining ceramic production processes, sources and exchange networks.

Keywords: Paracas, Necrópolis of Wari Kayan, ceramic analysis, wares, mortuary archaeology

${ }^{a}$ Colaboradora del Proyecto Prácticas en vida, presencia después de la muerte: lo estilístico y lo material en la Necrópolis de Paracas

Correo electrónico: vtinteroff@yahoo.fr 


\section{Introducción}

Las vasijas de cerámica son una fuente mayor en el estudio de las sociedades arqueológicas y han sido usadas para identificar culturas distintas, su cronología, su distribución geográfica, el contexto de su producción y las condiciones de vida cotidiana antes de permitir acercarse a las cuestiones de la organización social, económica y política de la sociedad a la cual pertenecen (Sinopoli 1991; Balfet 1966: 287). Entre 1927 y 1930, en la península de Paracas, Tello y Mejía Xesspe (1959, 1979) recuperaron 429 fardos funerarios en la necrópolis de Wari Kayan, con su ajuar funerario en un estado de conservación excepcional, que incluía a más de 500 vasijas en su gran mayoría enteras y, hasta ahora, muchas desconocidas. Estos fardos se atribuyen al período de "transición» ParacasNasca que puede ser fechado entre 200 a.C. y 100 d.C. (Unkel et al. 2007, fig. 2; Tinteroff 2008: 131-136) y abarcan a los estilos cerámicos Paracas Tardío (Ocucaje 10), Topará (Jahuay y Chongos) y Nasca Inicial (Nasca 1).

Los fardos estaban depositados aislados o en grupos dentro de fosas excavadas en rellenos, en niveles de ocupación y en construcciones más antiguas (Tello y Mejía Xesspe 1979; Peters, comunicación personal 2009). Dos depósitos funerarios principales, denominados "núcleos funerarios» A y B, contenían los fardos, cada uno formado por un individuo envuelto en textiles y acompañado de ofrendas al interior y al exterior, incluyendo vasijas de cerámica. Esta necrópolis ofrece un caso único en la costa sur para el estudio en conjunto de artefactos de distintos materiales (textiles, líticos, cerámicas, etc. $)^{1}$ y el análisis de vasijas en un mismo contexto funerario de la época de la «transición» Paracas-Nasca. La colección permite trabajar sobre tres niveles analíticos: 1) el del fardo funerario como unidad arqueológica (la asociación de los artefactos en un fardo); 2) el del sitio de Necrópolis como conjunto funerario en su secuencia cronológica (los fardos y sus ofrendas entre sí); 3) el del sitio de Necrópolis como parte integrante de un contexto regional multicultural (el estatus y el rol del lugar en la dinámica sociocultural regional). Mientras que el presente ensayo se enfoca sobre el material cerámico, no olvido que es una de las manifestaciones culturales de un grupo humano o social y que su análisis debe ser pensado, en su finalidad, dentro de un sistema más amplio (Balfet 1966: 288; Kubler 1970: 32).

Mis investigaciones desde 2005 hasta 2012 sobre la colección de vasijas procedentes de la península de Paracas y conservadas en el Museo Nacional de Arqueología, Antropología e Historia del Perú (MNAAHP, Lima, Perú), trataron de reunir los datos necesarios para determinar a qué tradiciones alfareras, tipos y fases pertenecen las vasijas de Necrópolis (Tinteroff 2005; 2008; $2011 \mathrm{a}$; 2011 b; 2012b) ${ }^{2}$. De las 115 vasijas que he estudiado hasta ahora, 44 provienen con seguridad del cementerio de Necrópolis. El análisis que aquí se presentada trata de integrar estas vasijas, en las secuencias cerámicas de la Costa Sur, generar interrogantes sobre el sistema de producción alfarera, sus funciones, la cronología del cementerio de Necrópolis, y preguntarnos acerca de las relaciones y de las organizaciones sociales de distintos grupos culturales reconocidos en la Costa Sur del Perú, llamados Paracas (fase tardía), Topará y Nasca (fase inicial). Si el presente ensayo no pretende responder a todas esas preguntas, se propone al menos evaluarlas y tratarlas en la perspectiva de la teoría desarrollada durante mi tesis doctoral. Las comparaciones de datos procedentes de varios contextos arqueológicos me llevaron a interpretar el período de la «transición» Paracas-Nasca, como la emergencia de una organización sociopolítica multicultural en el territorio del actual departamento de Ica, entre el final del Horizonte Temprano y el comienzo del dominio Nasca (200 a.C.100 d.C.), a la cual he denominado «mutación cultural multidireccional» (Tinteroff 2008). Esta se caracteriza por una diversificación cultural de las poblaciones Paracas, marcada por el desarrollo sincrónico de tres comunidades: Paracas (cerámicas Paracas-Ocucaje 9 y 10) que se mantiene en el valle de Ica, Topará (Jahuay y Chongos) en los valles de Chincha y de Pisco, y Nasca (Nasca 1) en la cuenca del río Grande de Nasca. Esa diversificación cultural tiene un marco geográfico, ya que cada grupo cultural va a asentarse en uno o algunos valles de la Costa Sur, manteniendo una red 
sociopolítica y económica estrecha, de la cual pueden dar prueba los depósitos de ofrendas en el cementerio de Necrópolis (Tinteroff 2008; 2009).

Si me alejo de la teoría de Peters en cuanto a la emergencia de Nasca a partir de las interacciones entre Paracas y Topará (Peters 1997; 2000: 245-246; 2008), concuerdo con ella cuando ve en la zona de Paracas «el centro político y ritual de una región frontera, tierra de encuentro para comunidades ${ }^{3}$ (Peters 2008), cuando interpreta la diversidad de las tradiciones de artefactos como prueba de entidades sociales distintas y cuando reconoce en contextos funerarios (particularmente de alto estatus) la combinación de artefactos de varias procedencias y de distintas fuentes culturales y sociales. Se piensa en Necrópolis en términos de pluri-cultural y de pluri-social al implicar a los tres grupos que son Paracas, Topará y Nasca. Si consideramos que Necrópolis fue alimentado durante unos 300 años, es importante poder determinar si las vasijas depositadas testifican de una secuencia cronológica de una misma cultura o tradición alfarera ${ }^{4}$ o si más bien el complejo refleja la interacción de varios grupos que depositaron las cerámicas en uno mismo momento o a lo largo del tiempo. En ese ultimo caso, es cuestión de identificar a qué tradiciones alfareras pertenecen las vasijas (¿Paracas, Topará y/o Nasca?), en qué proporción se encuentran y si se asocian a fardos distintos en cuanto al resto del ajuar funerario.

\section{Las vasijas de Necrópolis: una colección desconocida a revaluar}

Cuando Tello y Mejía Xesspe descubrieron en la península de Paracas, entre 1925 y 1930, las inhumaciones de los sitios que llamaron "Cavernas de Cerro Colorado» y «Necrópolis de Wari Kayan", identificaron dos fases de una misma cultura que bautizaron «Paracas» (Tello 1929; Tello y Mejía Xesspe 1959, 1979)5. A la primera fase, le dieron el nombre de "Cavernas» y a la segunda el de «Necrópolis». Caracterizan a la alfarería de Necrópolis por el uso del engobe y por la ausencia de decoración incisa y polícroma poscocción (Tello y Mejía Xesspe 1979: 472). No hicieron y tampoco publicaron un estudio completo de esas vasijas, solo divulgaron algunos dibujos y fotos de unos pocos recipientes que tienen un código de registro en 12/6 (Tello y Mejía Xesspe 1959: fig. 15, 23-26, 28, 30, lám. IX-C, XXVI-A-D, XXVII-B), además de unas vasijas sin el código especificado (Tello y Mejía Xesspe 1979: fig. 93). Hoy se puede calcular en 554 el número mínimo de individuos cerámicos (NMI), descubiertos y registrados con un código único por Tello durante sus excavaciones en Necrópolis, excluyendo a los numerosos tiestos de rellenos. Se puede evaluar en un promedio de $2 \%$ la cantidad de cerámicas de Necrópolis que fueron publicadas hasta 1979.

En las publicaciones de las décadas de los cincuenta y sesenta, las vasijas de Necrópolis están incluidas en distintos tipos, estilos o fases según el investigador y el lugar de la investigación: Paracas T-4 (fase del estilo Paracas), Jahuay 3 y Chongos (fases del estilo Topará), Nasca 1 (fase del estilo Nasca), Paracas tardío o Proto-Nasca de Strong ${ }^{7}$ (ver Rowe 1956: 147, 1958: 9-10, 139, 146; Strong 1957: 18, 21; Lanning 1960: 407, 427-28, 464-65, 578) $)^{8}$.

En 1964, Menzel, Dawson y Rowe publicaron la secuencia de las cerámicas Paracas de la zona de Ica, compuesta de las fases Paracas-Ocucaje 1 hasta 10 y Nasca 1, que está aún en uso y en la cual no integraron de manera oficial y formal las vasijas de Necrópolis. Sin embargo, como lo apuntó Peters (1997: 445), las cerámicas del tipo de Necrópolis han sido encontradas con cerámicas de la tradición Paracas Tardío y, entonces, han sido descritas como parte de las fases Ocucaje 10 y Nasca 1. Fue en esa época, que con mucha exactitud Lanning (1960: 465, 578) notó que «es evidente que, empezando en la época Paracas T-3 y siguiendo en el Período Intermedio Antiguo, hay una gran mezcla estilística en Cabeza Larga. El significado de ese conglomerado de estilos no es evidente, y quedará confuso hasta que unidades arqueológicas adecuadas sean aisladas y descritas. La identificación de las vasijas de la "Gran Necrópolis», y el estudio completo de sus asociaciones con los variados tipos de textiles, seguramente arrojarán luz sobre las relaciones entre las tradiciones Paracas-Nasca y Topará en esa área crucial. (...) Nuestro entendimiento de las relaciones culturales 
entre Ica y el área Topará habrá mejorado bastante si las cerámicas monócromas que acompañan a unas de las momias estuvieran identificadas definitivamente como Paracas T-4, Nasca 1, como Jahuay 3 y Chongos, o como una combinación de las dos tradiciones»?.

Es en ese sentido que, en los años ochenta, Peters estudió unas 150 vasijas procedentes de la península de Paracas, de las cuales unas 50 provenían de Necrópolis, y ofreció así la primera investigación de envergadura de las vasijas de Necrópolis (Peters 1997: 292, fig. 7.11, 7.17-18, 7.20, 7.22, 7.27, 7.29, 8.1; comunicación personal 2012). Luego de observaciones y comparaciones con vasijas de Pisco y de Ica, Peteres atribuyó la mayoría de las cerámicas de Necrópolis a la tradición Topará de la zona de Pisco (fases Jahuay 3 y Chongos) reconociendo sin embargo a unos tipos como más específicos a Necrópolis (Peters 1997: 286, 292, 441-566, 905-20). Desde entonces, varios investigadores adoptaron la interpretación desarrollada por Lanning y apoyada por Peters según la cual las cerámicas depositadas en Necrópolis serían de la tradición cerámica Topará (Van Gijseghem 2004: 12, 31-32, 38; Delgado Agurto 2007: 53; Dietz 2009: 37).

Cuando hice mi primera investigación sobre las cerámicas de la península de Paracas en 2005 en el MNAAHP, logré estudiar 20 vasijas que provienen de Necrópolis, ello con el fin de compararlas con las vasijas Ocucaje 10, Jahuay, Chongos y Nasca 1 (Tinteroff 2005, 2008). Las comparaciones con materiales publicados confirmaron las observaciones hechas por autores anteriores, es decir, que según las definiciones propuestas de las fases/estilos Ocucaje 10, Jahuay, Chongos y Nasca 1, las vasijas de Necrópolis se podrían atribuir a varias de ellas.

En 2008, Peters y Tomasto-Cagigao iniciaron el proyecto de investigación Prácticas en vida, presencia después de la muerte: lo estilístico y lo material en la Necrópolis de Paracas, sobre los fardos funerarios previamente abiertos o semi-abiertos de Necrópolis (Peters 2008; comunicación personal 2008-2012). Desde entonces, mis investigaciones sobre las vasijas de Necrópolis se inscriben dentro de los objetivos de ese proyecto, en cuanto a la síntesis de los datos de excavación y de inventario, y participan del análisis de los materiales en conjunto. Incluyen los depositados afuera de los fardos que son, en mi caso, las cerámicas (Tinteroff 2011a, 2011b), con el enfoque de:

- Redactar el inventario y construir una base de datos de las cerámicas Necrópolis, cruzando los datos procedentes de varias fuentes, como publicaciones y los archivos Tello (Peters 2007-2012; Tinteroff 2011a, 2011b) (contexto de ubicación, asociación de cada vasija dentro del complejo funerario, datos técnicos, decorativos, etc. relativos a cada vasija).

- Realizar una tipología propia que permita una verdadera comparación de esa colección, con las del sistema tipo-cronológico de la costa sur, una evaluación de su heterogeneidad vs. Homogeneidad; el análisis de la evolución del uso del cementerio en el tiempo, integrando la hipótesis de una variabilidad cultural y funcional de las vasijas.

Desde el inicio de mi investigación en 2012, se podía hacer importantes observaciones para el análisis de la colección de las vasijas de Necrópolis.

En primer lugar, las informaciones cruzadas procedentes de Tello y Mejía Xesspe (1929, 1959, 1979), de Peters (1997, 2007-2012), de los Libros de Inventarios del MNAAHP (vol. 9, vol. 10) y de los archivos Tello (Peters 2007-2012; Tinteroff 2011b; Tmx-625; Tmx-626; Tmx-635; Tmx-636 ${ }^{10}$ permiten inventariar un mínimo de 554 vasijas, cada una con su código único empezando con 12/ y que provendrían de Necrópolis. Hay que recordar que antes de ese trabajo de compilación de datos (y que se esta procesando aún), solo se podía evaluar en unas 80 vasijas la colección de Necrópolis basándose en lo disponible y en lo publicado. Este trabajo demuestra la importancia de la sistematización de la compilación de los datos de inventario, a partir de fuentes no publicadas, que son los inventarios de museos y los archivos.

En segundo lugar, las vasijas que fueron el objeto de un análisis más completo por Peters en los años ochenta (Peters 1997) y en 2011 (Peters, comunicación personal 2012) y por mí (Tinteroff 2005, 2011a), no pertenecen siempre a conjuntos arqueológicos específicos (o sea a la asociación a 
un fardo en particular, grupo de fardos, etc.) sino que constituyen una muestra heterogénea de la colección. En efecto, el análisis de las piezas, tanto en las investigaciones de Peters como en las mías, dependió de la accesibilidad a la colección en el museo y de la búsqueda, a veces infructuosa, de las vasijas en el Departamento de Cerámica. Se nota entonces, la importancia de buscar y de acceder a las piezas dentro del MNAAHP, incluyendo las vasijas en sala de exposición y las conservadas aún en los depósitos (Casareto Mognaschi, comunicación personal 2012). Es también necesario ubicar las vasijas que ya no están en el MNAAHP, pero que se encuentran en otras colecciones como en el Museo de la Nación de Lima (Peters comunicación, personal 2012; Dausse, comunicación personal 2012) o como las que fueron mandadas a Sevilla, España, en 1929 para la exposición universal y que, según lo que se sabe, nunca regresaron (Pérez Ponce, comunicación personal 2010; Peters 2007-2012; MNAAHP vol. 9: 189-19, vol. 10: 4, 7, 12, 22, 24) ${ }^{11}$.

En tercer lugar, las vasijas de Necrópolis no han sido aún objeto de una clasificación en sí, ya que, en el caso de las investigaciones de Peters, fueron integradas a la secuencia Topará gracias a comparaciones con el material de Pachinga y de Chongos en el valle de Pisco (Peters 1997) y que, en el caso de mis investigaciones, no fueron clasificadas por constituir una muestra demasiado reducida en cuanto a su número (Tinteroff 2005, 2008, 2011a). Quedaba claro la importancia de aumentar la muestra disponible y de desarrollar una metodología para el análisis de las vasijas en vista de su clasificación.

Fue bajo estas conclusiones que dirigí la investigación de 2012, sobre la colección de vasijas de Necrópolis de Wari Kayan, como colaborada del equipo investigador del proyecto dirigido por Peters y Tomasto-Cagigao. Estudié 21 vasijas procedentes de Necrópolis, adicionales a las ya estudiadas durante mis investigaciones de 2005 y de 2010, elevando a un total de 44 vasijas la muestra de la cual me está dada la oportunidad de presentar el estudio en este ensayo (Fig. 1).

\section{Marco teórico: las vasijas arqueológicas como fuentes antropológicas}

Varios autores reconocen en Ocucaje 8, Paracas Tardío (Ocucaje 9, 10), Topará (Jahuay, Chongos) y Nasca Inicial (Nasca 1), las manifestaciones culturales de un período de guerras (Van Gijseghem 2006: 428, 439; Reindel y Isla 2006: 241, 278; Castro Martínez et al. 2007: 128; Van Gijseghem y Vaughn 2008: 116, 124; Llanos Jacinto 2008; Stanish y Tantaleán 2012). En cambio, el comienzo de Nasca Antiguo (cerámicas Nasca 2 y 3) estaría marcado por la «elaboración de mecanismos sociales pan-regionales para reducir las guerras y aumentar las colaboraciones» ${ }^{12}$ (Van Gijseghem 2006: 439); lo que se materializa en la zona de Nasca, por una reducción de las construcciones en lugares defensivos y la creciente importancia de Cahuachi (Vaughn y Van Gijseghem 2007: 815). Este contexto bélico concuerda con mi teoría de la emergencia de núcleos culturales geográficamente diferenciados en la Costa Sur y con la transformación de las poblaciones paracas, hasta ahora de carácter homogéneo, en tres grupos culturales con sus tradiciones alfareras respectivas, y que los arqueólogos hemos llamado Paracas Tardío en Ica, Topará en Pisco-Chincha y Nasca Inicial en Nasca (Tinteroff 2008). Cabe mencionar aquí, que la contemporaneidad de las vasijas identificadas como Ocucaje 10, Nasca 1 y Chongos ha sido demostrada por varios autores (Tinteroff 2008: 101-124; Van Gijseghem y Vaughn 2008: 115; Castro et al. 2009: 147, 149; Hecht 2009: fig. 13.14) y que «lo que esta mirado como "cronológico" puede ser una expresión de estilos familiares o de grupos sociales diferentes» (Unkel et al. 2007: 553) ${ }^{13}$.

Se divide entonces el territorio entre esos tres grupos, que se van poco a poco diferenciando culturalmente los unos de los otros, tal como se refleja en sus producciones cerámicas, y que asientan su poder en sus valles (pueblos defensivos en Nazca, centros públicos de Chincha y Pisco, $c f$. Tinteroff 2008: 101-124). El desarrollo de centros de poder en cada valle, o agrupamiento de valles, se reconoce también, tras las influencias que se observan hacia otras regiones como en la Costa Central, donde se encontraron vasijas Topará, o bajo su influencia, en Villa El Salvador, Tablada de Lurín 
(Delgado 2007: 59-61, 75, fig. 22, 29, 31-32), Chillón y Ancón (Silva 1998: 265), lo cual identificó un abandono de los centros administrativos y ceremoniales, interpretado como el reflejo del «acrecentamiento en el prestigio y el radio de la influencia de la costa sur» (Delgado 2007: 75). Además, los patrones funerarios en la Costa Central no dejan de recordar los de Necrópolis — de los cuales son contemporáneos (Delgado 2007: 11-12)—, tanto en la posición del muerto, como de sus ofrendas cerámicas y su ubicación. De su lado, los descubrimientos de ocupación Paracas en la zona de Palpa y su secuencia respectiva con Nasca (Reindel y Isla 2006: 241, 249-250), así como recientes estudios de ADN en individuos de esa época (Fehren-Schmitz 2010: 342), van confirmando la teoría de los antecedentes Paracas de la cultura Nasca y el carácter autóctono de su emergencia, lo que puede apoyar mi teoría, alejándome de otras (Valdez 1988: 24; Silverman 2002: 147; Van Gijseghem 2004; Llanos 2008). Asemejo mi punto de vista a lo que los investigadores del Proyecto La Puntilla llamaron más recientemente, una «gestión política sincrónica de distintos objetos cerámicos singular y uso político-ideológico» (Castro et al., 2009: 151). En ese contexto, los distintos grupos sociopolíticos mantienen redes de intercambios y relaciones sociales, políticas y económicas estrechas, construyendo así un sistema social tal como lo definió Chicoine (2010: 192), en términos de interacciones, negociaciones y poderes. Así, el cementerio de Necrópolis, aislado de los valles agrícolas donde se asientan los poderes, puede ser definido como un lugar neutral participante de la cohesión regional, jugando un papel especial, de lugar sagrado donde se entierran a las élites de las diferentes comunidades (Tinteroff 2008: 140-146, 255-258). Podemos considerar, entonces, la hipótesis de que Necrópolis sea un centro de peregrinaje, siguiendo la definición de tales lugares propuesta recientemente por Kantner y Vaughn (2012: 66).

Entender a un conjunto cerámico, exige entender el contexto de su depósito. Si la cerámica es el primer material arqueológico usado para fechar las ocupaciones, en contextos funerarios vale la pena recordar que las vasijas pueden ser de distintas épocas, pero agrupadas en un mismo lugar durante un ritual particular, ser el producto de una misma comunidad o de varias, y haber sido hechas por y/o para la persona inhumada (Peters 1997: 441). Las vasijas son objetos «reflejo» de la persona inhumada que acompaña y/o de las personas que las depositaron (Peters 2000: 246) y permiten identificar a los estatus y roles sociales de los individuos que acompañan (Levy 1981: 181). Se puede considerar que «los comportamientos humanos hacia prácticas religiosas pueden reflejarse en la cultura material, independientemente del carácter a priori utilitario o no utilitario de los objetos» (Roux y Courty 2007: 153) $)^{14}$. Al haber sido depositadas con los muertos dentro de una necrópolis, las vasijas pueden ser consideradas como «ofrendas» o "depósitos» y deberían ser interpretadas en términos de función anterior a su uso funerario por una parte y, por otra parte, para y dentro del ritual funerario en el cual participan. Mientras Tello y Mejía Xesspe (1979: 337) atribuyeron un carácter ritual y no utilitario a las vasijas de Necrópolis, algunas, sobre todo los recipientes abiertos (platos, cuencos y escudillas), presentan características utilitarias en cuanto a sus cocciones, formas y acabados, y no parecen haber sido hechas expresamente para fines funerarios, a diferencia de otras, como las vasijas miniaturas y los cántaros de doble golletes. Sin embargo, es difícil aún identificar huellas de uso anterior en las vasijas de Necrópolis, como en otros contextos del Perú (Bernier 2009: 167), ya que, la colección estudiada ha sido lavada, manipulada varias veces y muchas de ellas, restauradas. En cuanto a su función, una vez depositadas en los contextos funerarios, uno puede interrogarse si la vasija en sí puede ser considerada como un objeto ritual, un tipo de efigie o ídolo que participa al culto de los ancestros (Lau 2008), o si solo sirve de contenedor de la ofrenda real ( $v . g$. alimentos, bebidas, etc.) siendo así, parte integrante, pero no especifica, de ese culto y de los rituales. Según lo reportado por Tello y Mejía Xesspe (1979: 336-337), las vasijas se encontraron afuera y adentro de los fardos, unas con vegetales y envueltas o no con tejidos. Hubiera sido interesante poder hacer un análisis de residuos, tales como se ha podido hacer en cerámicas de otros sitios (Cervantes 2010: 121; González et al. 2012) pero la colección de Necrópolis, por razones ya evocadas, no permite tal oportunidad. Sin embargo, considero que, al ser depositadas 
con los muertos, las vasijas, que pueden haber tenido un significado simplemente utilitario en su primer uso, "se descontextualizan de su espacio y significados y cobran un nuevo sentido" y que, como en varias otras sociedades, la cerámica en los rituales funerarios de las culturas de la costa sur puede ser evaluada como «semánticamente activa» (Albero 2009: 89-90).

Aunque algunas excepciones han sido mencionadas (Tello y Mejía Xesspe 1979: fig. 93), las vasijas en Necrópolis, han sido depositadas en su mayoría al lado del fardo funerario y no adentro. Así, no forman «exactamente» una unidad arqueológica con el fardo. Sin embargo, hacen parte de un ritual generalizado observado en el cementerio, el cual se puede interpretar como un área funeraria entendida como, «aquellos espacios naturales o modificados que delimitan estructuras funerarias interrelacionadas por forma, tamaño, orientación y contenido, lo cual sugiere una ocupación prolongada por grupos sociales autodefinidos por medio de estos conjuntos» (Cervantes 2010: 68-69). Aunque la costumbre de reabrir las tumbas para depositar nuevas ofrendas fue muy extendida en los Andes (Gerdau-Radonic 2007: 225), y ello deja abierta la posibilidad de que las vasijas fueran depositadas en diferentes momentos, posteriores al fardo funerario, no pienso que ese haya sido el caso en Necrópolis. Tomando en consideración que no todos fardos están inhumados en una estructura de arquitectura cerrada, sino que han sido introducidos en construcciones más antiguas, en rellenos y en la arena, la teoría de «sepultura abierta», tal como ha sido formulada por Isbell (1997), no parece adecuada para Necrópolis. Podemos considerar más bien, que las vasijas participan de los rituales funerarios al momento de la inhumación del fardo o de los fardos. Como fue sugerido para los entierros del Período Intermedio Tardío de Tablada de Lurín (Costa Central, cf. Gerdau-Radonic 2007: 228-229), y ello basándose en parte en documentos etnohistóricos, se puede sugerir que los fardos pudieron haber tenido un(os) primer(os) lugar(es) de descanso antes de ser llevados por distintos grupos hacia Necrópolis, como último lugar de descanso, en momentos particulares a lo largo del tiempo. Esta teoría se acerca a la formulada por Strong (1957: 16) y vale la pena mencionar aquí el descubrimiento hecho por Strong en Cahuachi, de grandes textiles, idénticos a los que envuelven los fardos de Necrópolis. Si se reconoce que un grupo homogéneo de tipos de vasijas acompaña a fardos funerarios no contemporáneos, entonces valdrá la pena considerar a esa hipótesis como válida. Las vasijas no habrían sido entonces siempre contemporáneas a los fardos, pero participan del ritual en el momento de la inhumación final de ellos.

$\mathrm{Mi}$ análisis de las vasijas de Necrópolis quiere inscribirse en una arqueología antropológica, tratando «ir más allá de la materialidad» y aproximarse a «las relaciones más tangibles que se producen entre cerámica, productores, usuarios y contextos de uso" (Vidal et al. 2009: 11-12). El estudio de las cerámicas arqueológicas sirve primeramente para determinar las condiciones técnicas de su fabricación, conocer al contexto de su producción y responder a las preguntas de procedencia y de cronología (Balfet 1966: 281-282). Determinar la organización social, política y económica subyacente a tal producción dependerá en gran parte de la identificación del contexto de esa producción (talleres artesanales versus producción familiar; v.g., cf. Balfet 1966: 289). Identificar la procedencia de las vasijas de Necrópolis es una meta en sí, recordando que si fueron producidas en el ámbito local (la península de Paracas) se espera poder encontrar la arcilla usada en proximidades (Shepard 1985: 337; Arnold 1975: 192), aunque que el acceso a la arcilla no es siempre un criterio de ubicación del lugar de producción (Nicklin 1979: 441-446). Como lo sugieren Castro y sus colaboradores (2009: 151), una vez identificados los lugares de producción y las redes que implican (actividad, distribución, saberes técnicos, socialización), se puede ir localizando "los territorios de uso de los productos, es decir, los lugares sociales donde acontecen actividades y prácticas normativas donde las cerámicas están en uso social». Sin embargo, no tenemos aún los datos para encontrar los lugares de producción de las vasijas de Necrópolis, en términos de análisis composicionales químicos ( $c f$. Ghezzi 2011), de fuentes de arcilla - debemos recordar que en la zona de Ica-Nasca una gran variabilidad de fuentes de arcilla ya fue ubicada (Vaughn y Neff 2000: 78) — y de estructuras ligadas a la producción de cerámica. 


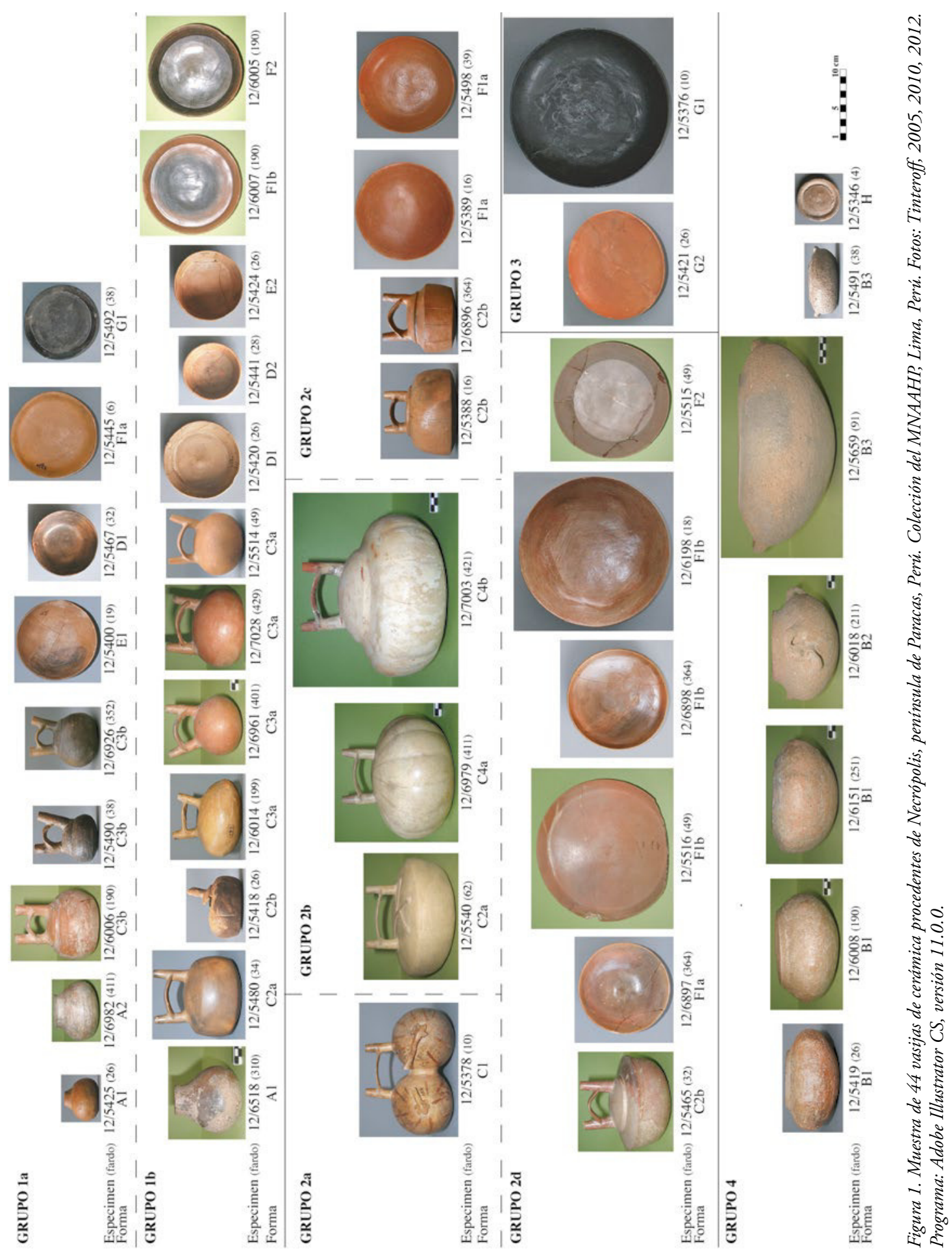


En efecto, quien dice producción cerámica dice residuos arqueológicos de tal producción (Sullivan III 1988: 23-24). Ahora bien, no se conocen o no se publicaron en detalle los datos relevantes a la artesanía alfarera de ese período en la costa $\operatorname{sur}^{15}$, a diferencia de los talleres que se pueden encontrar, por ejemplo, en la Costa Norte durante el período Mochica (Bernier 2009: 163). Encontrar tales lugares de producción permitiría evaluar con más seguridad el tipo de producción al cual nos enfrentamos, ya que la lectura de los diferentes factores de la alfarería (intensidad, grado, contexto, categorías, $c f$. Bernier 2009: 158) sería más completa. También podemos preguntarnos si las vasijas de Necrópolis fueron producidas en un contexto doméstico, o más bien por trabajadores especializados. La ausencia de vestigios ligados a la alfarería en un espacio especial puede ir en favor de la idea de producciones de tipo doméstico o doméstico-especializado, tal como fueron definidas por Santley, Arnold III y Pool (1989: 108-110). Sin embargo, esa ausencia puede ser respondida por nuevos descubrimientos arqueológicos mientras el análisis tecnológico-morfológico de las vasijas y de sus contextos de depósitos, pueden ayudarnos en validar la hipótesis.

El interés del análisis composicional ha sido demostrado repetidas veces (Shepard 1985: vi-ix; Rozenberg y Picon 1990: 9; Chapdelaine et al. 1997; Vaughn y Neff 2000, 2004; Glascock et al. 2004; Vaughn 2005: 119; Ruby y Shriner 2005; Vaughn et al. 2006: 686; Vaughn y Linares 2006: 598; Delgado 2007: 20, 42-43; Cervantes 2010: 110; Ghezzi 2011; Vaughn et al. 2011: 3560; Schneider et al. 2012: 192). Sin embargo, y hasta poder realizar tales estudios de forma complementaria, se considera que las técnicas usadas en la fabricación de las cerámicas, entendidas en la cadena operativa, responden a una selección de orden social y cultural y reflejan las diferencias entre las entidades sociales, al ser estas verdaderas reveladoras de identidades (Shepard 1985: 2; Roux y Courty 2005: 201), que deben ser entendidas como encarnadas en la cultura material (Demoule 1994: 474). Para reconstituir la cadena operativa y más generalmente entender el rol de las cerámicas, podríamos esperar ayuda de la etnoarqueología, que ha mostrado su interés repetidas veces en otras zonas del Perú o del mundo (Harry Tschopik 1950: 196; Levy 1981: 181; Druc 1996: 20). Sin embargo, datos consistentes utilizables para la Costa Sur faltan y, en ese contexto, no me parece adecuado comparar producciones de cerámicas de contextos temporales y geográficos tan alejados (Balfet 1966: 287). En cambio, el uso del análisis tecnológico-morfológico, aunque presenta limites para el estudio de nuestro corpus ya que estamos frente a una colección de vasijas en su mayoría enteras y restauradas, me parece adecuado a la luz de los resultados que puede ofrecer ya que «clasificando los conjuntos según las cadenas operativas implicadas en la fabricación de las cerámicas, son las diferentes entidades socioeconómicas productoras de esas cerámicas las que componen los conjuntos que son así puestas a la luz» (Roux y Courty 2007: 154, 156) ${ }^{16}$.

Es así que, inspirándome de la metodología usada para vasijas de los sitios calcolíticos del Levante Sur (Roux y Courty 2007: 153-154, 165, fig. 2), clasifiqué 44 vasijas de Necrópolis en cuatro grupos tecnológico-morfológicos a partir de las diferentes etapas de la cadena operativa (Fig. 1). Si el análisis revela que el conjunto cerámico en el contexto funerario de Necrópolis es heterogéneo, eso podría atestiguar producciones procedentes de diferentes grupos sociales y/o culturales en zonas geográficas aisladas. Por ejemplo, es así que se ha explicado la diversidad de las vasijas de una tumba del Horizonte Medio de la costa norcentral del Perú (Shady y Ruiz 1979: 681). En cambio, si es homogéneo, podrá reflejar una producción y un consumo más locales, que podrían ser o no producidas cerca del cementerio. Volvemos a preguntarnos si las vasijas encontradas en Necrópolis proceden de varios lugares y tradiciones alfareras, o si son el producto de una sola comunidad que participa de los rituales funerarios involucrados en la península de Paracas y, en los dos casos, ello implica consideraciones acerca del comercio o de la movilidad de las cerámicas (Shepard 1985: 354, 444; Massey 1986: 249-274; Bandy 2004: 97; Castro Martínez et al. 2009: 152). Sin embargo, hay que considerar que la variabilidad de los productos cerámicos encontrados en un mismo sitio puede explicarse por funciones diferentes o por productores diferentes que pueden ser identificados bajo varios niveles: el del taller o grupo social, el de los artesanos o de los 
individuos y el de los «segmentos temporales de un solo individuo» ${ }^{17}$ (Demoule 1994: 475-477). La ultima consideración es de importancia, en particular en la producción de las vasijas modeladas a mano que nos ocupa, en la cual la variabilidad en las partes de los recipientes (v.g. labios) puede ser más bien involuntaria que pensada. Basándose en los datos de pasta, forma, cocción y acabados, se puede tratar de identificar si estamos frente a una o varias tradiciones tecnológicas y si, en el primer caso, las variantes corresponden a varias unidades de producción entendidas como «personas que producen cerámica siguiendo técnicas aprendidas de generación a generación» (Cervantes 2010: $113-114)^{18}$.

\section{Contextualizar y clasificar la colección: metodología}

\subsection{El contexto arqueológico}

La primera tarea al trabajar con la colección de vasijas de Necrópolis consiste en encontrar las piezas dentro de los depósitos de los museos y los datos relevantes de su contexto original. La reconstitución del ajuar funerario de cada fardo funerario que fue abierto en el museo ha sido iniciada por Paul $(1990,1991)$ aunque no menciona las vasijas de cerámica. Fue seguida por varios investigadores quienes trabajaron sobre unos fardos ( $c f$. Aponte 2006: 10). Bajo el nombre de «recontextualización» y siguiendo trabajos iniciados por Peters en los ańos 2000 (Peters 2005-2006, 2007), Peters y Tomasto-Cagigao empezaron un amplio proyecto en 2008 para la reconstitución de la composición de cada fardo funerario de Necrópolis, incluyendo sus "ofrendas» externas (Peters 2008). Colaborando con este proyecto, he podido establecer una lista de 554 vasijas, cada una con su código que empieza con 12/ seguido de cuatro cifras, procedentes del cementerio de Necrópolis. Para evaluar la cantidad de la colección, usé la base de datos del proyecto de Peters y Tomasto-Cagigao (Peters 2007-2012), las publicaciones de Tello y Mejía Xesspe (1959, 1979), la tesis doctoral de Peters (1997), así como las versiones transcriptas por Ayarza Uyaco de los archivos Tello del Instituto Riva Agüero y registrados bajo las referencias Tmx-625, Tmx-626, Tmx-635 y Tmx-636. Usé también los archivos Tello del MNAAHP registrados bajo los nombres AT-162 y AT-168 y los volúmenes 9 y 10 de los Libros de inventario del MNAAHP (Tinteroff 2011a,b). Registré toda la información en una base de datos que elaboré usando el programa Filemaker.

La muestra que estudié de la colección de Necrópolis no fue realmente elegida, tal como debería ser el caso idealmente (Balfet 1966: 284), sino que fue más bien la disponibilidad de estas piezas dentro del MNAAHP, lo que permitió el estudio de algunas. En efecto, fue muy frecuente que ciertas vasijas no se encontraran en el museo o que otras no pudieran ser puestas a mi disposición en el momento deseado. Es por eso que la colección que presento parece muy heterogénea en términos de formas y de contextos, y a la vez muy homogénea en términos de conservación, ya que solamente se estudiaron vasijas enteras o restauradas. De otro lado, la variabilidad de las formas y de los contextos permiten suponer que la muestra estudiada es bastante representativa de la colección entera. Aunque sé que existen tiestos no restaurados, por ejemplo, en el Depósito G del MNAAHP (Casareto Mognaschi, comunicación personal 2012), no he podido, por el momento, estudiarlos. Se presenta aquí la clasificación de 44 vasijas (Fig. 1) de las cuales logré confirmar la procedencia, dejando de lado otras vasijas de las cuales no tengo aún los datos necesarios para asegurar que provengan de Necrópolis. Sin embargo, se mencionarán varios ejemplares que permitirán las comparaciones.

\subsection{La tecnología}

Idealmente, debería haber empezado a trabajar la colección de vasijas de Necrópolis bajo el criterio primeramente petrográfico tras la observación de las pastas usadas, recordando que es en la estructura interna donde queda lo más útil para determinar los tipos de alfarería (Balfet 1953: 214, 290). 
Sin embargo, no fue posible observar las pastas en roturas frescas ya que la colección se compone de vasijas enteras o fragmentadas pero restauradas. Solo se observaron gracias a una lupa digital en las superficies o en roturas no frescas ${ }^{19}$, lo que me permitió hacer algunas observaciones, pero que no pueden ser usadas para una clasificación petrográfica. Otro criterio posible para definir a grupos tecnológicos es el color de las vasijas o de la pasta. Sin embargo, cuando las vasijas han estado en contacto con el combustible, el color variará de una vasija a otra incluso si han sido hechas de la misma arcilla (Balfet 1966: 296). Es justamente el caso de numerosas vasijas de Necrópolis que presentan colores heterogéneos, con manchas negras o gris repartidas de manera irregular, lo que indica que las vasijas fueron cocidas en fuego abierto con una circulación diferente del oxígeno. Además, vale la pena notar que, en varios casos, los trabajos de restauración practicados sobre las vasijas en el pasado, modificaron el aspecto de la superficie sea en sus colores o su brillantez (v.g. plato 12/5376 y copela 12/5467; Tinteroff 2005: 79, 2012b). e a la colección que nos ocupa, se propone entonces usar los datos tecnológicos observables Frent y en particular los acabados de superficie (pulido, alisado, engobe), tomando en cuenta las limitaciones precitadas. Se propone cruzarlos con los datos morfológicos para poder llegar a grupos tecnológico-morfológicos coherentes, aun si las tradiciones técnicas han sido aquí parcialmente reconstituidas (Roux y Courty 2010: 7). Se entiende que cada grupo técnico se puede reconocer como una tradición técnica aprendida dentro de un mismo grupo cultural (Roux y Courty 2007: 158).

La clasificación tecnológica testimonia las operaciones de fabricación y de acabado (Roux y Courty 2007: 156-158, fig. 2). Todas las vasijas fueron modeladas a mano y presentan una cierta asimetría, unas más que otras (v.g. escudilla 12/5445 y cántaro 12/5490; Fig. 5), demás de conservar a veces las huellas del modelado en el cuerpo, lo que confirma la técnica usada. Por sus colores beige, naranja y marrón dominantes, las vasijas parecen haber sido cocidas en atmósfera oxidante, salvo el plato miniatura 12/5492 (Figs. 1 y 5) del cual el color gris negro podría considerarse que es resultado de una cocción en atmósfera reductora. Sin embargo, no es posible confirmarlo sin análisis de las pastas. Se pueden observar manchas negras en las superficies, generalmente externas, de la mitad del corpus. De formas irregulares, presentes sobre todo en las bases, esas manchas negras deben ser el resultado de la cocción, lo que podría indicar que la atmósfera de cocción cargada en oxígeno circulaba con dificultad entre las vasijas, en particular cuando estas estaban en contacto con el combustible (Balfet et al. 1983: 71; Peters, comunicación personal 2012). Por ser compuesto de vasijas enteras, mi corpus no autoriza los análisis necesarios para la identificación con más detalle de las operaciones de fabricación y de cocción. En cambio, permite usar al acabado como primer criterio tecnológico discriminatorio, observando las macromarcas (en francés: macrotraces) dejadas sobre las superficies internas y externas.

Las macromarcas dejadas por el alisado y por el pulido son observables en las superficies externas de los cántaros y en las superficies internas y externas de las vasijas abiertas, de las botellas y de las ollas. El alisado es la acción de igualar la superficie de una vasija o una parte de ella en estado húmedo, dejando una superficie llana y mate (Balfet et al. 1983: 85, 1988: 24-25). El pulido es la acción de igualar, gracias a fricciones repetidas, la superficie de una vasija o partes de ella al final del secado (Balfet et al., 1983: 87, 1988: 24-25). Resulta de ello un efecto de brillantez y una superficie ligeramente hundida. No fue fácil distinguir el alisado del pulido. Identifiqué las huellas de ranuras finas en superficies mates como el resultado del alisado, mientras que la superficie brillante y los surcos más o menos anchos y profundos con una superficie ligeramente irregular permitieron identificar el pulido. Otra dificultad en el análisis de los acabados fue el uso del engobe. El engobado es la acción de cubrir antes de la cocción la superficie de la vasija o una parte de esta con un revestimiento de naturaleza arcillosa (Balfet et al. 1983: 111, 1988: 24-25). En el caso de ciertas vasijas, no hay duda de que fueron recubiertas de un engobe (v.g. cántaro 12/6979 y escudilla 12/5389) pero, en otros casos, no se puede asegurar sin observaciones adicionales de tipo microscópico o en roturas frescas. Hasta poder realizar tales análisis, agrupé a las vasijas que se suponen sin engobe con 
las que identifiqué con una capa delgada de engobe (o self-slip, $c f$. Peters 1997: 495). Dentro del corpus, ciertas vasijas presentan un color de superficie negra que resulta de una cocción en atmósfera reductora o de un ahumado, lo que solo se podría confirmar observando las pastas. El ahumado es la acción de introducir humo negro en la capa superior de la arcilla y da una superficie negra (Balfet et al. 1983: 117). En el plato 12/5376 esa técnica fue combinada con la decoración por bruñido (patrón bruñido) de un motivo de líneas cruzadas formando una especia de «red» (Figs. 1 y 3). El motivo ha sido obtenido gracias al bruñido de la superficie al final del secado y antes de la cocción, técnica que da un motivo brillante sobre un fondo mate una vez ahumado.

Las otras técnicas de decoración no fueron consideradas como criterios discriminatorios, ya que en el corpus en cuestión son casos excepcionales (Fig. 1). El uso de elementos modelados aplicados (técnica del appliqué, cf. Balfet et al. 1983: 125) fue observado en el cántaro de doble cuerpo 12/5378, donde sirvió para representar los rabos de pepino, así cómo en la olla 12/6018, para hornear su cuerpo con un personaje con cabeza y brazos. La incisión, que es la acción de cortar la arcilla cruda para hacer una decoración (Balfet et al. 1983: 91), solo se observó en cuatro vasijas, a manera de pequeñas líneas finas horizontales en los golletes (cántaro 12/5378) o de líneas verticales en el cuerpo para imitar los surcos verticales de los zapallos (cántaros 12/5388, 12/5418 y 12/6896; Fig. 2). La decoración por modelado, que es la acción de decorar una vasija modificando los relieves de la arcilla plástica moviendo la materia (Balfet et al. 1983: 105), continúa siendo la técnica de decoración más representada en el corpus después del engobado. Se observó en varias vasijas sea para crear una base o un fondo umbilicado, imitando así a la forma de las calabazas o mates (copela 12/5420, escudillas 12/6005 y 12/6897; Fig. 3), para hornear al fondo (escudillas $12 / 5445$ y 12/6198), para dar un volumen con protuberancias al cuerpo de las ollas (12/5419, 12/6008 y 12/6151; Fig. 2) o para dar un volumen imitando al del zapallo en los cántaros (12/6979 y 12/7003; Fig. 1).

\subsection{La morfología}

En Necrópolis, Tello y Mejía Xesspe (1979: 337, fig. 93) reconocieron cinco formas generales de recipientes de cerámica que identificaron como «utilitarias y ceremoniales». Sin embargo, la definición de esas formas continúa siendo muy amplia e indefinida y no permite dar cuenta del panel de recipientes encontrados en Necrópolis. Determiné entonces las formas basándome en los criterios establecidos por Balfet y sus colaboradores (Balfet et al. 1983: 7-24, 1988), eligiéndolos por su claridad y su universalidad.

Reconozco en primer lugar, dos grupos principales que son las vasijas cerradas y las vasijas abiertas. Clasifico en el grupo de las vasijas abiertas a los recipientes que no presentan una constricción del diámetro (Fig. 3). El diámetro máximo es el de la boca, sin tener en cuenta una eventual hinchazón del labio (Balfet et al. 1983: 9). Se clasifican en las vasijas cerradas a los recipientes que presentan encima del diámetro máximo del cuerpo un diámetro inferior a este, que corresponda o no a el de la boca (Fig. 2). Después, se identifican dentro de esos dos grupos las formas de los recipientes a partir de la relación entre la altura y el diámetro máximo (Balfet et al. 1983: 7-24). Dentro de cada forma, definí los tipos y subtipos, los primeros entendidos como las formas intencionalmente repetidas (Delgado 2007: 21) y los segundos entendidos como las variantes de forma que se repiten. Consideré al perfil del cuerpo como el primer criterio de clasificación, el cual muchas veces va determinando el perfil de la base. En cambio, no consideré los bordes y los labios como elementos discriminatorios ya que ellos son muy variados, ya que casi cada recipiente tiene su forma propria de labio. Para describir las formas, usé por su claridad los términos de contornos, de estructuras y de volúmenes geométricos propuestos por Cauliez y sus colaboradores (Cauliez et al. 2001: fig. 1 y 2; Cauliez 2011). Todas las vasijas cerradas tienen contornos compuestos, es decir, son compuestas de un mínimo de dos volúmenes elementales y la unión entre ellos es hecha gracias a uno o más puntos de inflexión (Balfet et al. 1983: 24-28, fig. 6; Cauliez et al. 2001: 2-3). 
Figura 2. Vasijas cerradas de Necrópolis, peninsula de Paracas, Perú. Colección del MNAAHP, Lima, Perú. Dibujos: Tinteroff, 2012. Programa: Adobe Illustrator CS, versión 11.0.0.
Forma A

(Cantarito 12/5425)

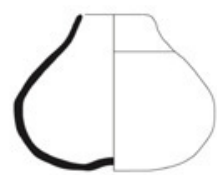

Forma B (Olla 12/5419)

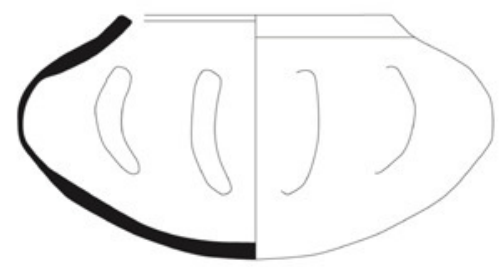

Forma C (Botella 12/5388)

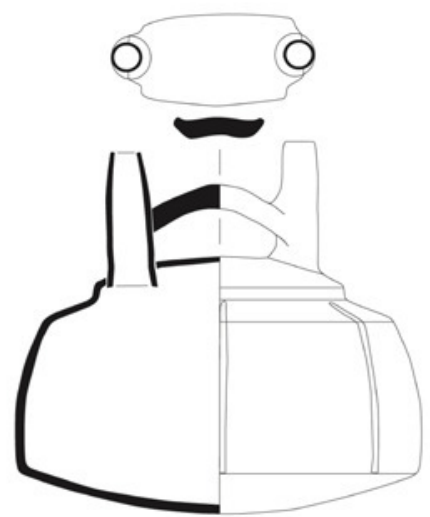

$10 \mathrm{~cm}$

Todas las vasijas abiertas son de contornos simples, compuestas de un volumen geométrico elemental y no tienen puntos de inflexión o de ruptura. Todas las vasijas estudiadas tienen un volumen geométrico esférico o cilíndrico, salvo la vasija de Forma H (12/5346) atribuible más bien a la forma discoidal y el cántaro de doble cuerpo 12/5378 modelado en forma de doble pepino y que tiene una forma elipsoidal.

\section{Resultados}

\subsection{Las formas}

Las vasijas cerradas incluyen las botellas (Forma A), las ollas (Forma B) y los cántaros (Forma C) (Figs. 1 y 2). Si las dos primeras habrían podido contener líquidos y sólidos, la tercera debió ser reservada a líquidos por no tener ninguna abertura aparte de la de los golletes.

Las botellas tienen un solo gollete central con un cuello cóncavo, carecen de asa y son de base redondeada o plana umbilicada. Corresponden a lo que Peters (1997: fig. 7.8) llamó necked bottle para las vasijas Topará de Pachinga y Chongos en el valle de Pisco. El conjunto incluye 3 ejemplares, todos de tamańo miniatura con una altura inferior a 8.7 centímetros y un diámetro máximo al cuerpo inferior a 9.2 centímetros. Las del tipo A1 son de cuerpo esférico (12/5425 y 12/6518; Figs. 1 y 2) mientras que la del tipo A2 es de cuerpo cilíndrico (12/6982, Fig. 1). 
Forma D

(Copela 12/5420)

Forma $\mathrm{E}$

(Cuenco 12/5424)

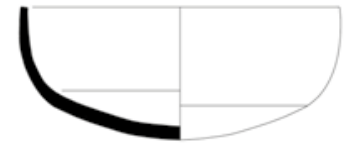

Forma $\mathrm{F}$

(Escudilla 12/6898)

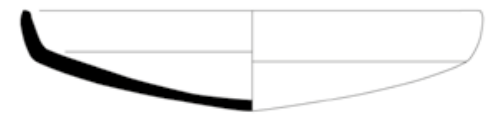

FORMA G (Plato 12/5376)

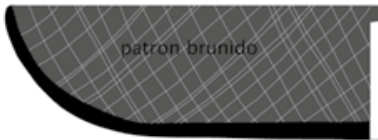

FORMA H

(Tapadera 12/5346)

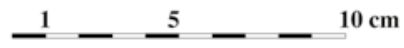

Figura 3. Vasijas abiertas de Necrópolis, península de Paracas, Perú. Colección del MNAAHP, Lima, Perú. Dibujos: Tinteroff, 2012. Programa: Adobe Illustrator CS, versión 11.0.0.

Las ollas son de cuerpo esférico, con cuello, de base redondeada, plana o ligeramente cónica. Corresponden a lo que Peters (1997: fig. 7.1-3) llamó neckless ollas ${ }^{20}$ para las vasijas Topará de Pachinga y Chongos en el valle de Pisco y se asemejan por la forma de los bordes a las ollas Chongos ilustradas por Lanning (1960 409: fig. 23I). El corpus incluye seis ejemplares con un diámetro promedio máximo del cuerpo de 14 a 15 centímetros, una altura promedia de 7 a 9 centímetros y un espesor entre 3 y 4 milímetros. Sin embargo, hay un ejemplar de tamańo miniatura (12/5491: diámetro máximo de 9 centímetros, altura de 3.8 centímetros) y un ejemplar grande (12/5659: diámetro máximo de 30.1 centímetros, altura de 13.4 centímetros) (Figs. 1 y 5). Las ollas del tipo B1 carecen de asas, son de cuello bajo y con el cuerpo con protuberancias modeladas (12/5419, 12/6008 y 12/6151; Figs. 1 y 2). La del tipo B2 tiene dos asas laterales y el cuello alto (12/6018; Fig. 1). Las del tipo B3 tienen dos asas laterales y un cuello bajo (12/5491 y 12/5659; Fig. 1).

Los cántaros son compuestos de un cuerpo de base redondeada o plana, sin cuello, y en su parte superior, dos golletes unidos por un asa más o menos arqueada llamada asa-puente. Es la forma cerrada característica de la costa sur del Perú, más conocida en inglés bajo el nombre de spouted bottle (Menzel et al. 1964) o de spout-and-bridge bottle (Peters 1997: 534). Los golletes están dispuestos en posición de «U», de «V» o en posición convexa. Son de perfiles muy variados: rectos, cóncavos, rectos y adelgazados. $\mathrm{El}$ asa se conecta con los golletes en su tercio inferior, a la mitad, o en su tercio superior. Tiene plantas y perfiles muy variados: perfil plano, ligeramente arqueado o muy arqueado, planta lenticular, rectangular, lenticular-rectangular o lenticular-cuadrangular. El corpus incluye 16 ejemplares con medidas muy variadas $(6.6 \mathrm{~cm}<$ diám. max. $<22.2 \mathrm{~cm} ; 7.90$ $\mathrm{cm}<$ altura $<18.7 \mathrm{~cm}$ ), considerando como vasijas miniaturas a las de un diámetro de cuerpo inferior 
de 13 centímetros (Fig. 1). Los tipos se pueden definir gracias al volumen geométrico del cuerpo y sus subtipos por la presencia o la ausencia de una "falsa tapa» situada en la parte superior del cuerpo, en la base de los golletes. El cántaro del tipo C1 es de doble cuerpo (12/5378; Fig. 1). Los del tipo C2 son de simple cuerpo cilíndrico, sin falsa tapa (subtipo C2a: 12/5480 y 12/5540; Fig. 1) o con falsa tapa (subtipo C2b: 12/5388, 12/6896, 12/5465 y 12/5418; Figs. 1, 2 y 4). Los del tipo C3 son de simple cuerpo esférico, sin falsa tapa (subtipo C3a: 12/6961, 12/5514, 12/6014 y 12/7028; Figs. 1 y 6) o con falsa tapa (subtipo C3b: 12/6926, 12/5490 y 12/6006; Figs. 1 y 5). Los del tipo C4 son de simple cuerpo, modelado en forma de zapallo, sin falsa tapa (subtipo C4a: 12/6979) o con falsa tapa (subtipo C4b: 12/7003) (Fig. 1).

Las vasijas abiertas incluyen las copelas (Forma D), los cuencos (Forma E), las escudillas (Forma F), los platos (Forma G) y las tapaderas (Forma H) (Figs. 1 y 3). Por ser mayormente acampanados y poco profundos, esos recipientes corresponden a las vasijas de servicios, destinadas a contener más bien sólidos que líquidos.

Las copelas son de perfil acampanado con un diámetro de la boca (inferior o igual a 11 centímetros) que se encuentra entre 2.5 y 5 veces la altura (Balfet et al. 1983: 11). Son de cuerpo esférico, con una carena en el tercio inferior, de fondo redondeado o casi plano y de labio plano o plano adelgazado. El corpus cuenta 3 ejemplares con medidas homogéneas $(7.9 \mathrm{~cm}<$ diám. max. $<10.6 \mathrm{~cm}$; $2.3 \mathrm{~cm}<$ altura $<3.1 \mathrm{~cm} ; 3 \mathrm{~mm}<$ espesor $<6 \mathrm{~mm})$. Las del tipo D1 son de paredes convexas $(12 / 5420$ y 12/5467; Figs. 1, 3 y 4). La del tipo D2 es de paredes rectas (12/5441; Fig. 1). Por la forma, corresponden a unas vasijas Topará clasificadas como bowl 7 y bowl 8 por Peters (1997: fig. 7.26, 7.28-29) en el valle de Pisco, así como a las vasijas Chongos descritas por Lanning (1960: 409).

Los cuencos son de perfil acampanado con un diámetro de la boca (inferior o igual a 18 centímetros) que se encuentra entre 1.5 y 2.5 veces la altura (Balfet et al. 1983: 13). Son de cuerpo esférico, sin carena, con labio plano o redondeado con bisel hacia el exterior. El corpus cuenta 2 ejemplares con medidas homogéneas $(9.6 \mathrm{~cm}<$ diám. max. $<11 \mathrm{~cm} ; 4.4 \mathrm{~cm}<$ altura $<4.5 \mathrm{~cm} ; 2$ $\mathrm{mm}<$ espesor $<4 \mathrm{~mm}$ ) (Figs. 1 y 3). El del tipo E1 tiene una base redondeada (12/5400). El del tipo E2 tiene una base cónica (12/5424; Fig. 3). Por la forma, corresponden a las vasijas Topará clasificadas como bowl 4 por Peters (1997: fig. 7.20-22) en el valle de Pisco. Se pueden también comparar con las vasijas Jahuay 1 ilustradas por Lanning (1960: fig. 22A-K) así como con las vasijas del Horizonte Antiguo 4 clasificadas como bowl 7 por Massey (1986: fig. 2.11) en el valle alto de Ica.

Las escudillas son de perfil acampanado con un diámetro de la boca (entre 12 y 22/23 centímetros) que se encuentra entre 2.5 y 5 veces la altura (Balfet et al. 1983: 11). Son de base plana, redondeada o ligeramente cónica, con un labio redondeado simple, adelgazado o con bisel externo o interno. El corpus incluye 10 ejemplares con medidas homogéneas $(12 \mathrm{~cm}<$ diám. max.<20.6 $\mathrm{cm} ; 2.9 \mathrm{~cm}<$ altura $<5 \mathrm{~cm} ; 3 \mathrm{~mm}<$ espesor $<6 \mathrm{~mm}$ ). Las del tipo $\mathrm{F} 1$ tienen un cuerpo esférico, sin carena (subtipo F1a: 12/5389, 12/5445, 12/5498 y 12/6897; Fig. 1) o con carena (subtipo F1b: $12 / 5516,12 / 6007,12 / 6198$ y 12/6898, Figs. 1, 3 y 6). Las del tipo F2 tienen un cuerpo cilíndrico con carena (12/5515 y 12/6005; Figs. 1 y 6). Por la forma, las escudillas se asemejan a las vasijas Topará clasificadas como bowl 2, bowl 7 y bowl 8 por Peters (1997: fig. 7.19-20, 7.26-29) en el valle de Pisco, a las vasijas Chongos descritas por Lanning (1960: 409, fig. 23E-F), a las cerámicas Paracas-Ocucaje 10 del valle de Ica identificadas como bowl 5 (Menzel et al. 1964: fig. 25) y a las vasijas del Horizonte Temprano 4, clasificadas como bowl 7 y bajo influencia Topará en el valle alto de Ica (Massey 1986: fig. 2.11).

Los platos son de perfil acampanado con un diámetro de la boca (inferior o igual a 23/24 centímetros) que es igual o superior a 5 veces la altura (Balfet et al. 1983: 10). Son de cuerpo esférico, con las paredes ligeramente convexas, con labio redondeado con bisel hacia el exterior o adelgazado. El corpus cuenta con tres ejemplares con medidas heterogéneas $(10.5 \mathrm{~cm}<$ diám. max. $<22 \mathrm{~cm}$; 1.6 $\mathrm{cm}<$ altura $<4.1 \mathrm{~cm} ; 4 \mathrm{~mm}<$ espesor $<7 \mathrm{~mm}$ ) y cuenta con un ejemplar miniatura (12/5492; Fig. 5). Los del tipo G1 son de base plana (12/5376 y 12/5492; Figs. 1, 3 y 5) mientras el del tipo G2 es de 
base redondeada (12/5421; Fig. 1). Por la forma, los platos corresponden a los llamados bowl 1 por Peters (1997: fig. 7.15-16, 7.18) para las fases Jahuay y Chongos de Topará en el valle de Pisco y se asemejan a los bowl 5b-2 Paracas-Ocucaje 10 en Ica (Menzel et al. 1964: fig. 25m) y bowl 5 de la fase Montana (o Nasca 1) de Nasca (Van Gijseghem 2004: fig. 5.11). Sin embargo, los ejemplares de Ica tienen paredes más rectas y los de Nasca paredes más convexas que las de los ejemplares de Necrópolis.

En mi corpus, la vasija 12/5346 permanece sin poder incluirse en ningunas de las formas precitadas (Figs. 1 y 3). Se caracteriza por un perfil muy achatado, una forma discoidal, una base redondeada y la ausencia de borde y de labio (forma $\mathrm{H}$ ). Se trata de una miniatura con un diámetro de 6 centímetros y una altura de 0.8 centímetros. Propongo que sea considerada una tapadera de una olla miniatura de la cual la 12/5491 es un ejemplo adecuado (Figs. 1 y 5) ${ }^{21}$. El estudio de más ejemplares permitiría confirmar la identificación de la forma.

\subsubsection{Los grupos tecnológico-morfológicos}

He reconocido 4 grupos tecnológico-morfológicos, definidos a partir de los acabados de superficies, internas y externas, con sus variantes respectivas (Fig. 1).

Grupo 1: pulido superficie externa, pulido superficie interna, con o sin una capa delgada de engobe. Formas: A, C, D, E, F, G

Las vasijas fueron dejadas «en bruto» o con una capa muy delgada de engobe (self-slip) y las superficies han sido pulidas en ambos lados. Hay dos variantes: pulido tosco con huellas más profundas en la superficie (variante 1a) y pulido fino con huellas menos visibles (variante 1b). En la variante 1a, se reconoce la subvariante 1a1, marcada por vasijas ahumadas parcialmente o totalmente, y la subvariante 1a2 en la cual el alisado queda en parte visible. En todos los casos, el pulido es generalmente esférico en el cuerpo y más por diagonales en la base. En el caso de las vasijas cerradas, solo se puede confirmar que la superficie externa ha sido pulida, al no ser visible la interna. Se observan manchas gris-negras de repartición y densidad irregular en todas las vasijas, lo que indica que fueron cocidas en fuego abierto con una circulación irregular del oxígeno, con exposición irregular al humo.

Ese grupo contiene la cantidad mayor de la muestra con 21 de las 44 vasijas del corpus, incluyendo a nueve de los 16 cántaros (Fig. 1). Otras vasijas de los sitios de Paracas pertenecen a ese grupo mientras no puedo aún confirmar sus procedencias exactas. A la variante $1 \mathrm{a}$, se pueden agregar las botellas 12/7036 y 12/6554 (tipos A1 y A2), los cántaros 12/6203, 12/7239 y 12/6733 (subtipos C3a y C2b), el plato miniatura 12/5674 (tipo G1) y la copela 12/5675 (tipo D1) (Tello y Mejía Xesspe 1959: lám. XXVI-C; Tinteroff 2005: 38, 45, 107; 2011a: 10, 12; 2012b). La subvariante 1a1 incluye la copela miniatura 12/6883 (tipo D2) y el plato miniatura 12/7037 (tipo G1) (Tello y Mejía Xesspe 1959: lám. XXVI-B; Tinteroff 2005: 32-33). A la variante 1b, pertenecen los cántaros 12/7273 (subtipo C3a) y 12/6784 (subtipo C2b), el plato 12/6221 (tipo G2) y la escudilla 12/6769 (subtipo F1b) (Peters 1997: fig. 7.27c; Tinteroff 2005: 95, 108-109, 116). Se puede además integrar al grupo 1 una serie de escudillas procedentes de Cerro Colorado, península de Paracas (12/6356, 12/6342, 12/6366, 12/6576, 12/6338 y 12/6341; Tinteroff 2005: 59-63, 73) aunque presentan algunas particularidades, lo que podría indicar variaciones cronológicas dentro de un mismo grupo tecnológico.

Grupo 2: pulido fino en superficie externa, pulido en superficie interna con una capa gruesa de engobe. Formas: $\mathrm{C}$ y $\mathrm{F}$.

Las vasijas están recubiertas de una capa espesa de engobe en ambos lados, salvo en los cántaros en los cuales solo la superficie externa recibió el engobe. Han sido finamente pulidas, con pocas marcas del pulido observables. El pulido es generalmente de orientación esférica en el cuerpo, 
circular o por diagonales en la base, y vertical en los golletes de los cántaros. Manchas gris-negras en poca densidad y de repartición irregular se observan sobre algunas piezas indicando que fueron cocidas en fuego abierto con una circulación irregular del oxígeno, aunque con un mayor control de las condiciones de cocción que para las vasijas del grupo 1. Reconozco cuatro variantes en el grupo 2, aisladas por el color del engobe usado: engobe rojo y naranja-crema (variante 2a), engobe crema (variante $2 \mathrm{~b}$ ), engobe naranja (variante $2 \mathrm{c}$ ), engobe rosado-violeta (variante $2 \mathrm{~d})^{22}$.

Ese grupo contiene una cantidad importante de vasijas del corpus con 14 de los 44 ejemplares, que incluyen siete de los 16 cántaros y siete de las 10 escudillas (Fig. 1). Otras vasijas de los sitios de Paracas pertenecen a ese grupo mientras no puedo aún confirmar su procedencia exacta. A la variante 2a, pertenecen los cuencos 13/142 y 12/5256 (tipo E1) los cuales se particularizan por el perfil convexo al borde y, para el primero, por la presencia de dos asas laterales, acercándolos a la forma de la olla (Tello y Mejía Xesspe 1959: lám. IX-A; 1979: fig. 67; Tinteroff 2005: 51, 74). A la variante $2 \mathrm{~b}$, pertenecen los cántaros 12/6015, 12/6445 y 12/7257 (subtipos C4b, C4a y C2b) (Tello y Mejía Xesspe 1959: lám. XXVII-B; Peters 1997: fig. 8.1a; Tinteroff 2005: 39, 85). A la variante 2c, pertenecen el cántaro 12/6280 (subtipo C2a), el cual se particulariza por el perfil muy acampanado de sus golletes, así como la escudilla 12/6291 (subtipo F1a), los dos ejemplares procedentes de la Caverna VI de Cerro Colorado (Tinteroff 2005: 57-58). La variante 2d incluye al cántaro 12/7299 procedente de Arena Blanca (subtipo C2b) (Tinteroff 2005: 111).

Grupo 3: alisado superficie externa, pulido en superficie interna. Forma: G.

Las vasijas del grupo 3 tienen la superficie externa alisada, lo que ha dejado ranuras paralelas muy finas con una superficie mate, y la interna finamente pulida, de un modo que es poco visible y deja una superficie brillante (Fig. 1). Se reconocen dos variantes. En la primera (variante 3a), la superficie interna está cubierta de una espesa capa de engobe. En la segunda (variante 3b), la superficie interna ha sido ahumada dándole un color negro, por lo que el ahumado se ha extendido hacia el labio y el borde externo.

$\mathrm{Al}$ nivel de formas, ese grupo incluye solamente a los platos pero mi muestra es muy reducida (2 ejemplares). Otras vasijas de la península de Paracas pertenecen a la variante $3 \mathrm{~b}$ aunque no puedo aún confirmar su procedencia exacta. Se tratan de los platos del tipo G1 numerados 12/7231 y 12/5631 así como de los platos del tipo G2 numerados 12/5304, 12/6235, 12/7019 y 12/7230 (Peters 1997: fig. 7.17a, 7.18a; Tinteroff 2005: 88, 103, 114-115, 127).

Grupo 4: pulido tosco superficie externa, alisado en superficie interna, engobe grumoso en superficie externa. Formas: $\mathrm{B}$ y $\mathrm{H}$.

La superficie interna ha sido alisada sin otro acabado, dejando rayas muy finas sin orientación particular. La superficie externa está recubierta de un engobe naranja claro compuesto de arcilla mezclada con numerosas inclusiones antiplásticas de hasta 2 milímetros de diámetro (lo que identifico como un "engobe grumoso») y que da a la superficie un aspecto muy grumoso y rugoso (Fig. 1). La superficie externa ha sido alisada y el alisado es visible en el cuello bajo la forma de finas líneas paralelas, y toscamente pulida en el cuerpo. Las pastas contienen numerosas inclusiones antiplásticas de hasta 2 milímetros de diámetro, observables a simple vista, y que incluyen una proporción importante de mica. Ese tipo de pasta fue observado solamente en ese grupo, con las formas $\mathrm{B}$ y $\mathrm{H}$. Las vasijas tienen unas manchas negras gris de repartición y densidad irregulares en las superficies externas e internas que indican una exposición irregular al humo durante la cocción. En cambio, no presentan huellas de quemaduras debidas a un uso sobre fuego.

Las vasijas de ese grupo son homogéneas en término de forma ya que se cuentan solo las ollas, así como la tapadera, la cual identifico como la de la olla miniatura 12/5491 o de otro espécimen no estudiado pero similar. Otras ollas de la península de Paracas pertenecen a ese grupo mientras no puedo aún asegurar sus procedencias exactas: 12/5439 (tipo B1), 12/5676 la cual forma un cuarto subtipo (subtipo B4: con asas, de cuello bajo, con el cuerpo con protuberancias modeladas), 
12/7025 (tipo B3) y 12/7537 la cual forma un nuevo subtipo (B5: sin asas, de cuello bajo, cuerpo sin protuberancias modeladas) (Tinteroff 2005: 36, 89; 2011a: 8; 2012b).

\subsubsection{Contexto arqueológico: los assemblages}

Según Mejía Xesspe (Tmx-626: 46), los objetos de cerámicas estaban «colocados adelante cerca de los pies sobre los pliegues del tejido funerario debajo de la estera, los cantaritos están boca arriba, los platos con la boca hacia abajo cubriendo sustancias alimenticias ya sean independientes o puestos en platitos de junco o mimbre y amarrados con una servilleta rala. (...) Los cántaros también están asegurados por medio de hilos de algodón o por medio de tejidos ralos especie de chumpi». Aun cuanto es interesante esa descripción, continúa siendo de orden general. Además, en su mayoría, las descripciones de los fardos y de su excavación, sea en las publicaciones (Tello y Mejía Xesspe 1959, 1979) o en los archivos Tello, no siempre incluyen la descripción del contexto de las vasijas. Estoy todavía agrupando los datos contextuales referentes a la totalidad de las vasijas de Necrópolis y sería prematuro proponer aquí una síntesis sobre el total de la colección. A continuación, proponga más bien algunos comentarios sobre los contextos de las vasijas de mi corpus, incluyendo unas vasijas adicionales.

La primera dificultad en estudiar al contexto arqueológico de las vasijas de Necrópolis es que existen incoherencias entre las descripciones de las piezas en los archivos o en las publicaciones y la pieza real estudiada, lo que hace dudar de que se trata de la misma pieza. Hay ejemplos como el cántaro 12/6200, el cuenco 12/7089 y el cuenco 12/7116 (Tello y Mejía Xesspe 1979: 331; MNAAHP vol. 10: 8; Tinteroff 2005: 92, 94; 2012b; Peters 2007-2012; Tmx-635: 57-58, 60). En esos casos, se puede suponer errores de numeración en las referencias bibliográficas o en las vasijas mismas. Esa última explicación se ha confirmado en el caso de la escudilla 12/6898 ( ${ }^{\circ} \mathrm{C} 16058$ en el MNAAHP; Fig. 3), la cual originalmente llevaba el número erróneo 12/6818 (Perez Ponce, comunicación personal 2012). Otras incertidumbres se deben a las incoherencias entre diferentes fuentes, ya que en una se menciona a la vasija y su asociación mientras que en la otra no se anota. Hay ejemplos como el cántaro 12/6203, las vasijas atribuidas al fardo 113 y el cuenco 12/6443 (Tmx-626: 21 vs. MNAAHP vol. 10: 8; MNAAHP vol. 9: 191 vs Tmx-625; AT-162 vs Tello y Mejía Xesspe 1979: 362 vs Tmx-635: 5). En otros casos, la vasija ha sido atribuida a un fardo funerario en particular, mientras que en realidad proviene de desmontes o rellenos, lo que puede dejar dudas en cuanto a su depósito primario. Existen ejemplos como las copelas 12/6883 y 12/7037 originalmente atribuidas al fardo 451 (Tello y Mejía Xesspe 1979: 332-333, 347; MNAAHP vol. 10: 22; AT-163; Tmx-635: 61; Tmx-636: 158). También, según Tello y Mejía Xesspe (1979: 386), las cuatro vasijas registradas con el fardo 190 (12/6005-8, Fig. 1) $)^{23}$ fueron encontradas en el relleno que enterraba al fardo. En cambio, según el archivo Tmx-625, se encontraron tres vasijas envueltas en un tejido, y dicho paquete había sido encontrado debajo de los tejidos de algodón hacia el lado norte. Parece que es bajo esa última descripción que Aponte (2006: fig. 3) propuso una reconstrucción que dejaría pocas dudas sobre el contexto arqueológico del fardo 190 y de sus ofrendas cerámicas, aunque dejó anotadas incoherencias entre diferentes fuentes. Es difícil, en ese contexto, confirmar que esas vasijas fueron intencionalmente depositadas con y como ofrendas a ese fardo, pese a que ello es probable. Otro caso interesante es el de las vasijas que fueron atribuidas a un fardo, en casos en que el contexto de excavación de ese fardo puede ser cuestionado. Tal es el caso por ejemplo del cuenco 12/6923 atribuido al fardo 358 (MNAAHP vol. 10: 23) al tiempo que es mencionado en otra fuente (Tmx-635: 44) que ese fardo se deshizo cuando se excavó el 357. Un caso similar se encuentra con los fardos 110 y 112 a los cuales se atribuyeron vasijas como ofrendas externas (MNAAHP vol. 9: 190-191). Sin embargo, esos fardos se cayeron durante la excavación del fardo 89 (Tmx-625) lo que puede dejar dudas en cuanto a la asociación contextual entre las vasijas y los fardos. 


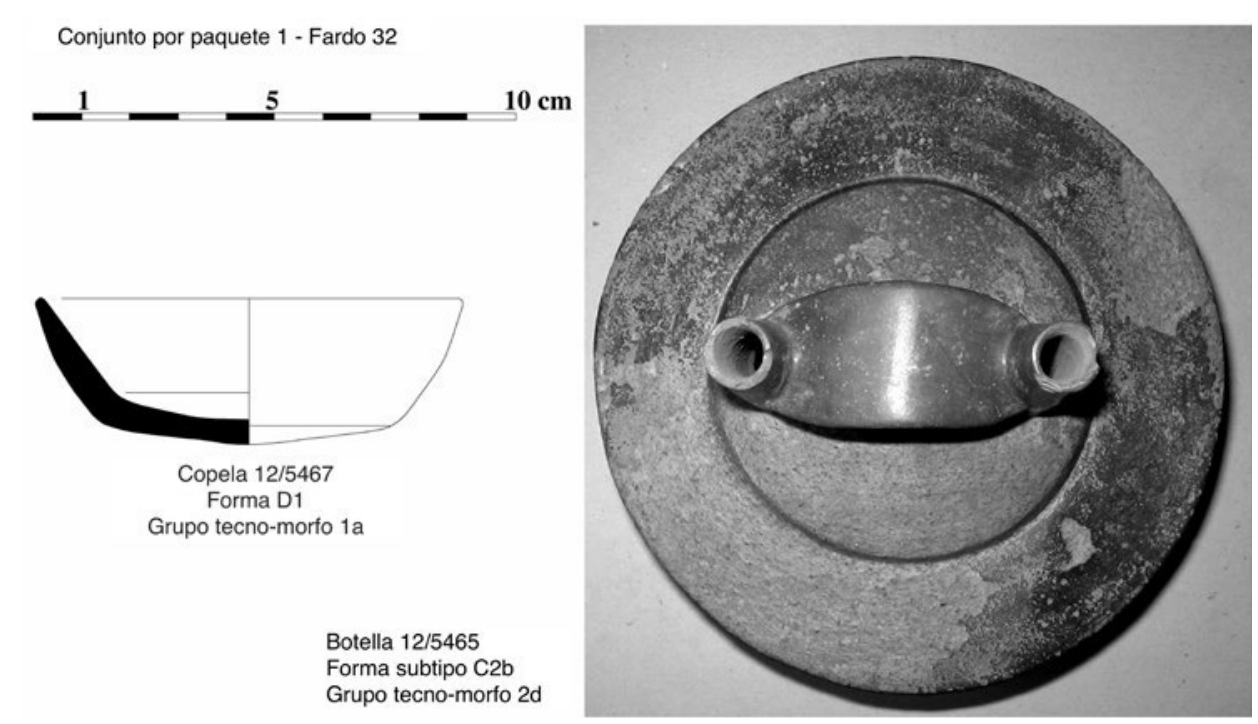

Figura 4. Vasijas del assemblage por paquete no 1. Fardo 32, Necrópolis, península de Paracas, Perú. Colección del MNAAHP, Lima, Perú. Dibujos y fotos: Tinteroff, 2005, 2012. Programa: Adobe Illustrator CS, versión 11.0.0.

En otros casos mucho menos dudosos, la descripción de la ubicación de las vasijas es generalmente muy evasiva. Es así que las vasijas identificadas como ofrendas al fardo 32 (Fig. 4) fueron descritas como encontradas «al pie» del fardo, depositadas dentro de un mate con yuca, todo envuelto en un tejido (Tmx-626: 41). También se mencionan unos cántaros en el lado norte de los cuales el espécimen 12/5469 podría ser un ejemplo (MNAAHP vol. 9: 188). Seis vasijas fueron identificadas como ofrendas exteriores del fardo 26 (Fig. 1). Una botella (12/5425) y un cuenco (12/5424) fueron encontrados al oeste del fardo y debajo de él, mientras que un cántaro (12/5418), una olla (12/5419), una copela (12/5420) y un plato (12/5421) fueron encontrados a su lado norte (Tmx-626: 37). Igualmente, de las dos vasijas atribuidas al fardo 10, el cántaro 12/5378 fue encontrado a sus pies por su lado oeste mientras que el plato 12/5376, el cual estaba enrollado en un tejido, se ubicaba en su lado norte (Tmx-626: 23; MNAAHP vol. 9: 185) (Figs. 1 y 3). Las vasijas depositadas con el fardo 15 (olla 12/5439 y escudilla 12/5440) fueron encontradas a su lado oeste (Tmx-626: 26). La escudilla 12/6198 (Fig. 1), también apareció al lado oeste del fardo 18 (Tmx626: 28). Finalmente, cabe anotar que numerosas vasijas se encontraron depositadas al lado norte de los fardos, pero no todas.

El breve resumen de la ubicación original de las vasijas en los depósitos funerarios de Necrópolis, nos llevan a unos comentarios de importancia en cuanto al contexto arqueológico de las vasijas de la colección estudiada. Aunque el depósito de vasijas al norte de los fardos aparece como recurrente, ello no es exclusivo ya que se mencionan depósitos en otros lados, como al Oeste. Entonces, no parece adecuado reconocer aquí una constante en cuanto a la ubicación de las vasijas como ofrendas a los fardos. Sin embargo, el estudio permite ya reconocer una cierta constancia en el depósito de las vasijas en Necrópolis, es decir, cerca al fardo y hacia su lado norte, noroeste u oeste con una predominancia del norte. Además, es muy importante señalar que los datos disponibles son muy pocos y poco detallados y, en la mayoría de los casos, incompletos o dudosos. Estos no permiten reconstruir de manera segura el contexto de depósito original de las vasijas y, en ese caso, sería poco convincente estudiar las vasijas de Necrópolis en una perspectiva de microunidad arqueológica representada por el fardo. En otras palabras, pocos son los ejemplos de asociación directa entre una(s) vasija(s) y un fardo en particular y, aunque se reconoce una calidad cierta en la excavación y en su registro ${ }^{24}$, 
podemos dudar de la viabilidad de los datos contextuales reportados en las publicaciones y los archivos. La fuerte proximidad de los fardos unos con los otros, mezclados en un relleno de tierra, arena y desperdicios, no ayuda además a validar la asociación de las vasijas depositadas en tal relleno con determinados fardos en particular.

Entonces, para la colección estudiada en este ensayo, y partiendo de lo particular a lo más general, se pueden agrupar y reconocer los distintos grupos contextuales llamándolos «conjuntos» y reconociendo tres tipos: conjuntos en paquete (agrupamiento de vasijas en un tejido que los envuelva, formando una unidad arqueológica viable; Figs. 4, 5 y 6); conjuntos por fardo (depósito de vasijas al lado de un fardo, identificadas por Tello y Mejía Xesspe como las ofrendas de ese fardo, que forman una unidad arqueológica cuestionable); conjuntos por agrupamiento de fardos (vasijas que proceden de un espacio reducido dentro de la Necrópolis, determinadas por la cercanía de los fardos entre sí, que forman una unidad arqueológica hipotética, $c f$. Peters, comunicación personal 2009).

Los conjuntos en paquete son un agrupamiento de vasijas envueltas en un tejido que puede o no contener restos vegetales ${ }^{25}$. En efecto, aunque no es una regla, hay una constancia en el depósito de las vasijas dentro de un tejido que las envuelva, sea sola (v.g. plato 12/5376, fardo 10; Figs. 1 y 3 ), o en conjunto con otras vasijas formando paquetes que fueron encontrados al lado del fardo. Esas vasijas forman una unidad arqueológica en sí, que puede ser o no asociable a un fardo en particular. De las vasijas que hasta hoy estudié, se puede analizar tres conjuntos en paquete que son los de los fardos 32 (Fig. 4), 38 (Fig. 5) y 49 (Fig. 6) (Tello y Mejía Xesspe 1959: lám. IX-C; 1979: 321; Peters 1997: fig. 7.29c, 8.1e; Tinteroff 2005, 2011a, 2012b; Tmx-626: 41, 51, 55; MNAAHP vol. 9: 188). Otros conjuntos que se pueden analizar son los por fardos de los fardos 10, 16, 26, 190, 364 y 411 por haber estudiado la totalidad de las vasijas, aparte del 364 del cual me falta estudiar la vasija 12/6899 (Tmx-626: 23, 27, 37; Tmx-635: 45, 53; MNAAHP vol. 9: 185-187; vol. 10: 3, 22, 24; Tello y Mejía Xesspe 1979: 386; Peters 1997: fig. 7.20c, 7.27b, 7.29b, 8.1c; Tinteroff 2005, 2011a, 2012b; Aponte Miranda 2006: fig. 7-10).

Los conjuntos por agrupamiento de fardos se pueden analizar a través de la cercanía de los fardos funerarios dentro de Necrópolis, es decir estudiar en conjunto las vasijas que proceden de un espacio reducido dentro del cementerio, fijándose en los grupos contextuales propuestos por Peters (comunicación personal 2009).

\section{Ensayo de interpretación}

El grupo tecnológico-morfológico 1 con sus dos variantes (Fig. 1), se caracteriza por la diversidad de las formas que abarca, lo cual muestra que las técnicas usadas no dependen de la función del recipiente. Más bien, la cadena operativa común para recipientes de formas diferentes indica que estamos frente a un solo grupo sociocultural de producción. Todas las botellas (forma A) pertenecen a ese grupo, sin embargo, el corpus es muy reducido. El pequeño tamaño de las vasijas es característico, lo que refleja una homogeneidad en cuanto a las medidas, con una gran mayoría de vasijas miniaturas que incluyen a los cántaros (forma C). De manera general y en términos de «Medida de los Niveles de Producción» (MNP; en inglés: Production Step Measure, cf. Feinman et al. 1981), las vasijas del grupo 1 son las que exigieron la menor cantidad de etapas en su producción, como se observa en la escasez de técnicas de acabado y de decoración, más allá del engobado (self-slip) y el pulido, aunque algunos ejemplares llevan incisiones (cántaro 12/5418), o recibieron un decorado por modelado en la base para imitar a los mates (copela 12/5420, botella 12/5425 y escudilla 12/6005). Los colores de las vasijas varían poco y son en su mayoría naranja claro, con manchas negras gris, aunque existen algunos ejemplares con un ahumado parcial $(12 / 5490 \mathrm{y}$ 12/6926) o total (12/5492), lo que indica una probable cocción en fuego abierto, poco controlada, con una mala circulación del oxígeno. 
Conjunto por paquete 2 - Fardo 38

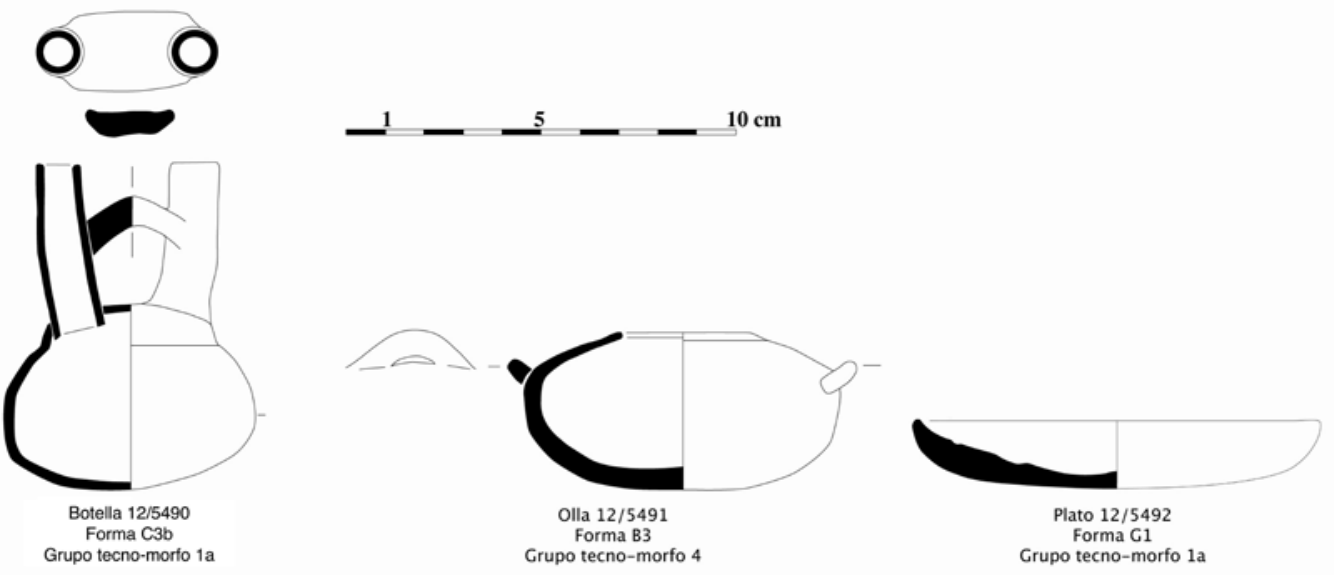

Figura 5. Vasijas del assemblage por paquete no 2. Fardo 38, Necrópolis, península de Paracas, Perú. Colección del MNAAHP, Lima, Perú. Dibujos: Tinteroff, 2012. Programa: Adobe Illustrator CS, versión 11.0.0.

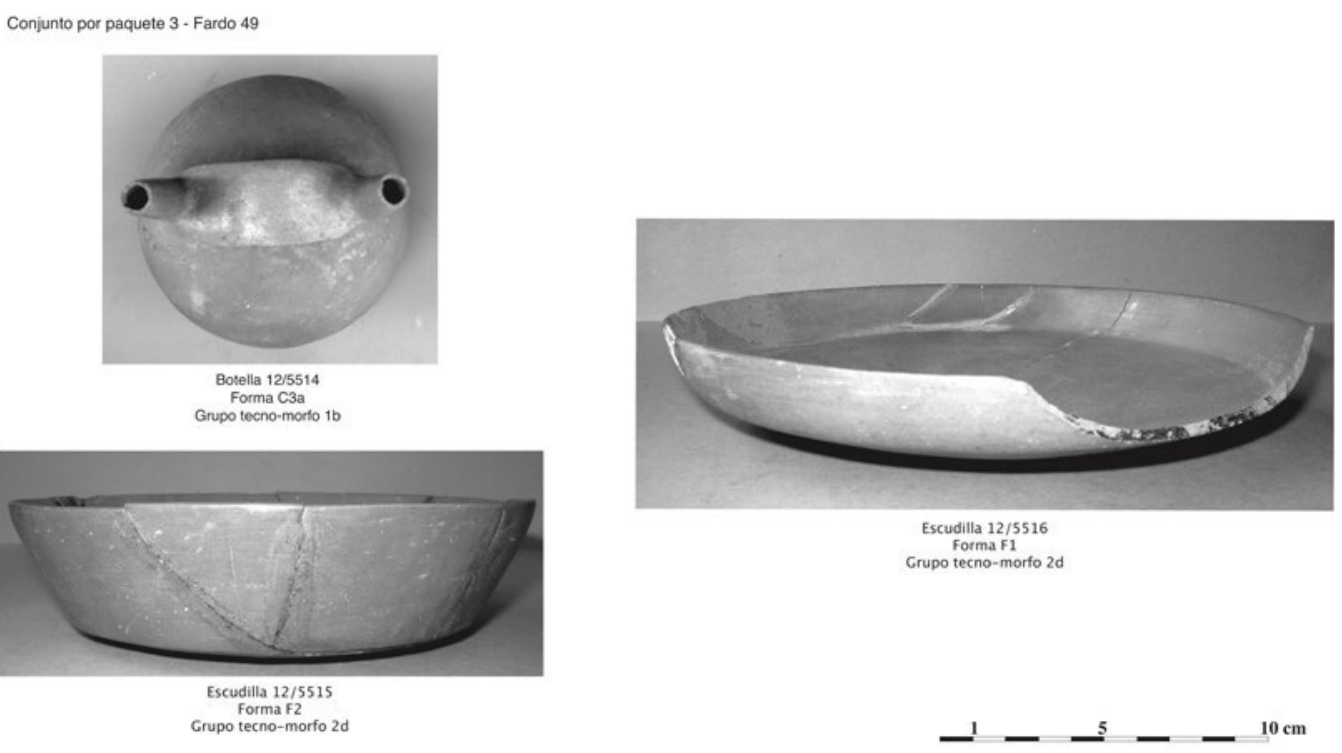

Figura 6. Vasijas del assemblage por paquete no 3. Fardo 49, Necrópolis, península de Paracas, Perú. Colección del MNAAHP, Lima, Perú. Fotos: Tinteroff, 2005, 2010. Programa: Adobe Illustrator CS, versión 11.0.0.

Las vasijas de las fases Jahuay 3 y Chongos del valle de Pisco ofrecen las mejores comparaciones con las del grupo 1 de Necrópolis (Peters 1997: 485-486, fig. 7.8). Corresponden a los tipos Topará Burnished y Topará Fine Oxidized de Peters (1997: 495, 908) en el valle de Pisco. Los cántaros tendrían que ser comparados a los pocos tiestos de los tipos Wari Kayan Modeled y Wari Kayan Blackware de la fase Chongos de Pachinga, a fin de averiguar si estamos frente a un mismo grupo de producción (Peters 1997: 535, 538). Sin embargo, el tamaño miniatura de la gran mayoría 
de las vasijas del grupo 1 así como su factura tosca indican que se puede tratar más bien de imitaciones en miniatura de vasijas Jahuay 3 y Chongos de la tradición Topará, procedentes de contextos domésticos en Pisco. Se pueden identificar las miniaturas como vasijas hechas para los rituales funerarios ya que no se encuentran en contextos domésticos (Peters 1997: 295, 562; Vaughn 2005: 120). También es interesante la interpretación de las vasijas miniaturas propuesta por Costin y por Rucabado, y resumida por Cervantes (2010: 33-36), según la cual fueron depositadas por la gente común de la comunidad de la cual han sido enterradas las personas de alto rango o de rango social más alto, y eso con el fin de participar del ritual y mostrar sus lazos con los muertos de su comunidad.

Siguiendo esas observaciones, sugiero que las vasijas del grupo 1 fueron producidas localmente, con fines mayormente rituales por gente de un rango social bajo o medio, pertenecientes a la tradición cultural Topará de la zona de Chincha-Pisco. Fueron producidas para ser depositadas con los muertos de un rango social más alto al momento de su inhumación en Necrópolis, como objetoofrenda. La manufactura de las vasijas del grupo 1, indica una producción homogénea en términos culturales, por lo que las variantes pueden resultar de habilidades diferenciales entre individuos y/o tener más bien una explicación cronológica.

El grupo tecnológico-morfológico 2 se diferencia fácilmente del grupo 1 por tener menor diversidad de formas, con solamente cántaros y escudillas, el tamaño de las vasijas más grande, aunque existen cántaros miniaturas, también tienen una combinación más compleja de técnicas de acabado y de decoración en términos de MNP (Fig. 1). Es el grupo en el cual se puede reconocer la mayor diversidad de técnicas decorativas (incisión, modelado, engobado, appliqué), usadas en las mismas formas, particularmente en los cántaros. El grupo 2 se caracteriza por un número reducido de formas, así como por la heterogeneidad de los colores de los engobes y de las técnicas de decoración usadas. A diferencia de las vasijas del grupo 1, las del grupo 2 presentan pulidos mucho más finos, así como pocas manchas gris-negras lo que indica un mayor control de la cocción.

Las vasijas del grupo 2 pueden ser comparadas a las Jahuay 3 y Chongos identificadas por Peters en la zona de Pisco, bajo los tipos Wari Kayan Cream-Slipped y Topará Oxidized, incluyendo su variante Chongos Rosado a la cual corresponde mi variante 2d (Peters 1997: 495, 505, 535, 909). Los cántaros pueden ser comparados también a ejemplares Paracas T-4, Paracas-Ocucaje 10 y Nasca 1 de la zona de Ica (Menzel et al. 1964: fig. 23A-c) de los cuales algunos provienen de las tumbas excavadas por Aldo Rubini Drago (especímenes H-1, 1-5, K-4, J-5, 28-1, C-1, Museo Regional de Ica, cf. Tinteroff 2012a; Peters 1997: fig. 8.2a, 8.2c). Se pueden también encontrar puntos de comparación en la zona de Nazca, tal como en Cahuachi, donde existen unos pocos ejemplares con engobes crema, naranja y naranja-crema (Tinteroff 2008: fig. 105, 113, 141). Sin embargo, las vasijas abiertas de Necrópolis se diferencian de las Ocucaje 10, Montana o Nasca 1 en Nazca, en particular por la forma que es mucho más convexa que acampanada en Nasca (Isla et al. 2003: fig. 22; Van Gijseghem 2004: fig. 5.11, 5.13).

El grupo tecnológico-morfológico 2 se puede reconocer como homogéneo en términos de formas y heterogéneo en términos de técnicas de acabados y de decoración. Además, los puntos de comparación posible a lo largo de la costa sur, que abarcan los valles de Pisco, Ica y Nazca, me llevan a proponer que las vasijas del grupo 2 provienen de diferentes grupos de producción al nivel macroregional, lo que comprende a la gente de las tradiciones cerámicas Jahuay 3 y Chongos en Pisco, Paracas-Ocucaje 10 y Nasca 1 en Ica y en Nazca. Las vasijas de la variante $2 \mathrm{~d}$ (engobe rosado-violeta) tienen sin embargo más elementos de comparación con las producciones de la zona de Pisco (variante Chongos Rosado de Peters) lo que me hace proponer que estas fueron producidas por gente de la cultura Topará, probablemente en la zona de Pisco. El grupo 2 tiene una cantidad dominante de cántaros con unos ejemplares en miniatura. Como las miniaturas, los cántaros se encuentran muy raramente en contextos no funerarios (Van Gijseghem 2004: 261; Delgado 2007; Gerdau-Radonic 2007: 10). Aparecen como productos hechos con fines funerarios y las técnicas 
de acabado y de decoración usadas indican una producción hecha por especialistas. Las diferencias que pueden existir de un cántaro al otro podrían explicarse en términos de grupos de producción distintos de las tradiciones alfareras Paracas, Topará o Nasca 1, o también en términos cronológicos. La homogeneidad de las formas del grupo 2 indican que este es funcionalmente homogéneo, con producciones a fines funerarias.

El grupo tecnológico-morfológico 3 es muy reducido en termino de corpus ya que esta representado por solamente dos vasijas (Fig. 1). No se puede aún proponer comparaciones con la vasija de la variante 3 a pero si existen puntos de comparación con la de la variante $3 \mathrm{~b}$ caracterizada por el ahumado interno con decoración por patrón bruñido (Fig. 3). Según lo publicado, se asemeja más a las vasijas de las variantes Jahuay Interior Smudged y Chongos Interior Smudged del tipo Topará Smudged, aislado por Peters en Pisco (Peters 1997: 496, 910-911, fig. 7.14). En cambio, se diferencia bastante de las vasijas Nasca 0 (Orefici y Drusini 2003: 144; Tinteroff 2008: fig. 112), Stylus Decorated (Strong 1957: 24) o Montana Reduced Convex y Nasca 1 Blackware (Van Gijseghem 2004: fig. 5.11; Vaughn y Van Gijseghem 2007) de la zona de Nazca o de Ica (Massey 1986: 74, fig. $2.11 \mathrm{~b}-\mathrm{c}$ ), por no haber sido cocidas en atmósfera reducida, sino solamente ahumadas al interior y por las formas de los recipientes. Es muy prematuro interpretar aún al grupo tecnológicomorfológico 3, ya que contamos con solo dos ejemplares, pero es interesante anotar que el grupo cuenta solo con la forma de los platos con tamańos bastante grandes respeto a las vasijas abiertas de los dos primeros grupos, lo que podría indicar que no son vasijas funerarias en su primer uso, y que las mejores comparaciones se encuentran con las cerámicas Jahuay 3 y Chongos de la zona de Pisco.

El grupo 4 se aísla de los demás por las técnicas usadas (el engobe grumoso en particular) con formas limitadas ya que solo contiene a las ollas y a la tapadera de olla (Fig. 1). Es entonces un grupo homogéneo, que se puede interpretar en términos funcionales. Aún no he encontrado descripciones o ilustraciones en las publicaciones que puedan permitir identificar las vasijas del grupo 4 fuera de Necrópolis. Aunque los tamaños son más reducidos, las vasijas de ese grupo tendrían que ser comparadas a las ollas del tipo Topará Scraped identificadas por Peters en Pachinga y Chongos pese a que estas parecen carecer del engobado grumoso (Peters 1997: 472-480, fig. 7.1-5). El espesor de las ollas de la colección de Necrópolis es de un promedio de 3 a 4 milímetros, lo que podría permitir buscar comparaciones con las ollas del valle de Ica descritas por Massey para su fase Horizonte Temprano 4, pero la composición de la pasta, más fina en los ejemplares de Ica, no parece indicar una misma producción (Massey 1986: 83-84, fig. 2.12a-b). Para la fase ParacasOcucaje 10, se mencionan unas ollas decoradas con protuberancias (Menzel et al. 1964: 215) pero no tengo fotos o dibujos que autoricen dichas comparaciones.

El grupo 4 puede ser interpretado como el producto de un solo grupo, cultural y socialmente uniforme. El hecho de que las vasijas no presenten huellas de uso al fuego, así como sus tamaños reducidos, llevan a suponer que no fueron usadas para cocinar. Se podría tratar quizá de imitación de ollas de cocina producidas por un grupo que identificamos como posiblemente local y socialmente uniforme ya que no se encuentran ejemplares comparables fuera de la península de Paracas. En esa perspectiva, sería particularmente importante poder estudiar el material cerámico procedente de los contextos domésticos de la península de Paracas (Tello y Mejía Xesspe 1979; Engel 1992).

Las vasijas miniaturas de los grupos 1 y 4 fueron depositadas en el «conjunto en paquete» del fardo 38 (Fig. 5), mientras vasijas de los grupos 1 y $2 \mathrm{~d}$ aparecen en conjunto en los «conjuntos en paquete» de los fardos 32 y 49 (Figs. 4 y 6 ).

Primeramente, se observa conjuntos de vasijas heterogéneos en términos de formas. Después, recordando que tales conjuntos forman unidades arqueológicas válidas, es interesante observar que aparecen en conjunto las vasijas de los grupos que identifico como procedentes de una producción local, de tradición Topará (fases Jahuay 3 y Chongos), de rango social bajo y medio (grupos 1 y 4) y de una producción más especializada, procedente de la zona de Pisco e igualmente atribuida 
al grupo cultural Topará (grupo 2d). Es necesario hacer el análisis de más «conjuntos en paquete» para ver si la asociación de esos tres grupos es una recurrencia, o si las vasijas de los otros grupos se encuentran también en tales paquetes. Hasta entonces, se puede reconocer una homogeneidad cultural y social tras las vasijas depositadas en paquetes, producto de una misma comunidad afiliada a Topará.

Observaciones comparables se pueden hacer en cuanto a los «conjuntos por fardo» cuando las vasijas no fueron depositadas en paquete, pero al lado del fardo aun si forman una unidad arqueológica cuestionable. Sin embargo, en esos "conjuntos por fardo", aparecen las vasijas de los grupos 2a, 2b, 2c y 3, depositadas con las de los grupos 1, 4 o $2 \mathrm{~d}$, lo que indica una heterogeneidad más fuerte en términos de grupos de producción. Sobresale también en unos casos la ausencia de vasijas de los grupos 1 y 4 con unos fardos. Es el caso de los conjuntos de los fardos 10, 16 y 364 . Con el fardo 16, encontramos vasijas exclusivamente del grupo 2c, mientras que con el 364 se trata de vasijas del grupo 2 (variantes 2 c y $2 \mathrm{~d}$ ). Con el fardo 10 , se encontraron las vasijas de los grupos $2 \mathrm{a}$ y $3 \mathrm{~b}$.

Bajo los ejemplos mencionados, se puede notar entonces dos tipos de depósitos principales: uno con la mezcla de producciones locales (grupos 1 y 4 ) y macrorregionales (grupos 2 y 3); el otro con producciones exclusivamente macrorregionales. Al nivel más amplio de los «conjuntos por agrupamiento de fardos", se nota una fuerte mezcla de las vasijas de todos los grupos tecnológicosmorfológicos, sin que se pueda reconocer aún algunas recurrencias.

La clasificación tecnológica-morfológica de las vasijas de Necrópolis y su análisis por conjuntos, permiten sugerir la existencia de tres producciones alfareras principales de las cuales las vasijas fueron depositadas en el cementerio, lo que indica una cierta heterogeneidad en términos de grupos socioculturales. Sin embargo, en el corpus estudiado se nota la predominancia de las producciones de afiliación Topará (fases Jahuay 3 y Chongos), lo que confirma las conclusiones de Peters (1997: 286, 292, 295, 299, 441-566, 905-920).

La primera producción alfarera, atribuible a las poblaciones de cultura Topará de rango social bajo y medio, que vivían probablemente en la península de Paracas, puede ser definida como local y hecha para los rituales funerarios, por lo que las vasijas fueron destinadas a ser depositadas con los fardos al momento de su inhumación. Está representada por las vasijas del grupo tecnológicomorfológico 1. Son probablemente imitaciones de vasijas usadas en contextos domésticos Topará durante el período Jahuay 3 y Chongos, y fueron manufacturadas muy probablemente al lado del cementerio de Necrópolis en hornos abiertos simples, durante el ritual de entierro de los fardos. Las vasijas del grupo tecnológico-morfológico 4 pueden ser identificadas como pertenecientes a esa misma producción alfarera por encontrarse en conjunto con las vasijas del grupo 1, y no tener comparaciones fuera de la península de Paracas. Sin embargo, propongo considerar que se trata de una producción socialmente aparte ya que abarca una sola forma funcional de vasijas con un tipo de acabado especial determinado por el engobe grumoso.

La segunda producción alfarera también puede ser identificada con la tradición cerámica Topará de las fases Jahuay 3 y Chongos, pero con un cierto grado de especialización (acabados más complejos, técnicas de decoración más variadas, control de la cocción) y formas ya no tan miniaturas lo que sugiere un probable primer uso doméstico anterior. Después, fueron reusadas en contexto funerario en Necrópolis donde fueron depositadas por gente de rango social medio o alto que vivían en los sitios Topará de la zona de península de Paracas/Pisco/Chincha. Esta producción esta representada por las vasijas de las variantes 2 c y $2 \mathrm{~d}$ del grupo 2 , y por las vasijas del grupo 3 , piezas que hasta ahora tienen sus mejores puntos de comparaciones en los contextos Topará de Pisco.

Finalmente, la tercera producción alfarera se caracteriza por su heterogeneidad en términos de acabados y decoración frente a la predominancia de la forma C (cántaros). Esa producción está representada esencialmente por los cántaros del grupo 2 (variantes $2 \mathrm{a}$ y $2 \mathrm{~b}$ ) reconocidos como producciones a destino funerario y que tienen puntos de comparación en varias zonas de la costa sur atribuibles a las tradiciones Topará en Pisco, Paracas Tardío y Nasca 1 en Ica-Nazca. Se propone 
que esas vasijas fueron producidas en contextos macrorregionales, por grupos domésticos especializados (cf. definición de Santley et al. 1989: 108-110) perteneciente a tres grupos culturales distintos (Paracas, Topará y Nasca) y que conocieron una movilidad a larga escala para los rituales funerarios involucrados en Necrópolis.

\section{Conclusiones}

El análisis de 44 de las 550 vasijas de Necrópolis muestra el fuerte interés de esa colección para el estudio del período de "transición» Paracas-Nasca y su potencial para el entendimiento de las producciones alfareras en la Costa Sur y de las redes de interacción de las que participan. Los límites de las conclusiones de este artículo son evidentes ya que se necesitan otros análisis adicionales, en particular en cuanto al fechado de esas cerámicas y de su procedencia, ya que como lo apuntó justamente Johnson (1977: 482), la distribución de los artefactos permite reconocer las interacciones de poblaciones, pero solo si se conocen los centros de producción.

Sea para la cronología, como para la procedencia, el análisis de las vasijas de Necrópolis quedará incompleto hasta que sean analizadas en conjunto con los otros datos de cada fardo, tal como se lo propone el proyecto de Peters y Tomasto-Cagigao, lo que permitirá determinar si los grupos cerámicos pueden corresponder a grupos de rangos sociales distintos y a fardos de diferentes épocas. Además, se necesita aumentar la muestra de vasijas de Necrópolis estudiada para compararla con vasijas presentes en conjuntos en contextos habitacionales y rituales (basurales y rellenos arquitectónicos), en contextos de producción (o con evidencia de producción de alfarera) y en contextos mortuorios del período «transicional» Paracas Tardío, Topará y Nasca Inicial en la costa sur del Perú (Peters y Tinteroff, comunicación personal 2009-2013).

Las vasijas de Necrópolis tienen que ser consideradas en una perspectiva regional y las comparaciones con materiales procedentes de otros sitios pueden confirmar o corregir mis interpretaciones. Es así que se necesita compararlas con las vasijas procedentes de las otras zonas funerarias de la península de Paracas y de los contextos domésticos, así como las exhumadas de los sitios de los valles de Chincha, de Pisco y de la zona de Nazca (Tello y Mejía Xesspe 1979; Massey 1986; Engel 1992; Cook 1994; DeLeonardis 1997; Peters 1997; Van Gijseghem 2004; Castro Martínez et al. 2007: 129-130; 2008: 186; Peters y Van Gijseghem 2008; Tinteroff 2011b; Peters et al. 2012; Van Gijseghem et al. 2013: 290). Tales análisis comparativos implican el registro de las pastas, de las formas y de los acabados de superficie y técnicas de decoración, incluyendo los análisis composicionales. Permitirían acercarse a las cuestiones de las relaciones de intercambio social (¿proceden las vasijas de Necrópolis de centros poderosos o de centros domésticos afuera de la península de Paracas?), de la función particular de un o unos tipos de vasijas respecto a un grupo social que los produce (¿son consumidas esas vasijas por el grupo "productor»?), y del modelo de organización social propuesto para la distribución de las vasijas y de su evolución durante el período de «transición» Paracas-Nasca (¿los cambios en el tipo de producción indican cambios en el tipo de organización socio-política y económica?) (Peters y Tinteroff, comunicación personal de 2009-2013).

En esa perspectiva, el uso de la arqueometría parece interesante (Vaughn, comunicación personal 2012) ya que puede permitir localizar a las fuentes de los componentes, o por lo menos aislar grupos composicionales los unos de los otros, y evaluar así los movimientos de vasijas y al grado de interacción entre las poblaciones productoras (Rozenberg y Picon 1990: 9; Vaughn y Neff 2000: 80; Glascock et al. 2004: 95; Vaughn et al. 2011: 3560; Schneider et al. 2012: 192). Estamos frente a una colección de vasijas en su mayoría enteras de las cuales puede que no sea permitido el análisis de pastas, aunque estas técnicas fueron usadas con éxito sobre otras colecciones (Delgado Agurto 2007: 20). Sin embargo, se podrían realizar la clasificación petrográfica y análisis arqueológicos sobre las vasijas no restauradas y previamente clasificadas en los grupos tecnológico-morfológicos, que son los tiestos que podrían encontrarse en el Depósito G del MNAAHP 
(Casareto, comunicación personal 2012). La investigación continuará aún incompleta hasta que se puedan localizar las fuentes de las arcillas lo que exige un estudio geológico detallado de la región y un análisis mineralógico (Balfet 1966: 294) tal como se ha podido hacer en la zona de Nazca (Vaughn y Neff 2004: 1577; Glascock et al. 2004), aunque existen numerosas limitaciones para localizar los lugares de producción de las cerámicas (Nicklin 1979: 441-446; Vaughn y Neff 2000: 86-87). Sería además necesario encontrar a los restos arqueológicos de producción alfarera en asociación con fuegos o estructuras de cocción, y tratar de determinar las condiciones de cocción de las vasijas para ver si se pueden suponer variables, siguiendo los ejemplos de la costa norte (Cervantes 2010: 110), así como la función primera de las vasijas, usando por ejemplo los análisis de permeabilidad (Balfet 1966: 298-299). Además, si recordamos a Hally (1986: 267), determinar la función de las vasijas permitiría confirmar cuáles fueron producidas para rituales funerarios, y cuáles para un uso doméstico, y así someter nuestras hipótesis e interpretaciones a esos resultados.

\section{Agradecimientos}

Agradezco a Ann H. Peters y Elsa Tomasto-Cagigao por la oportunidad de colaborar en su proyecto de investigación, por su confianza, ayuda y por haber compartido conmigo tantos datos y documentos. Expreso mi gratitud a todos los profesionales e investigadores del MNAAHP, Lima, quienes me facilitaron siempre el trabajo. Durante los ocho años de mis investigaciones que preceden a este ensayo, son innumerables todas las personas que me ayudaron y que, de una manera o otra, participaron en la construcción de mis pensamientos, me permitieron acceder a los datos que necesitaba y me facilitaron su análisis. Que sean aquí muy sinceramente agradecidas.

\section{Notas}

1 Lo que se propone hacer el Proyecto Prácticas en vida, presencia después de la muerte: lo estilístico y lo material en la Necrópolis de Paracas, dirigido por Ann H. Peters y Elsa Tomasto-Cagigao.

2 Realicé la investigación de 2005 en el marco de mi doctorado, las de 2010 y de 2011 como investigadora independiente y la de 2012 como colaboradora al proyecto de Peters y TomastoCagigao. Innumerables discusiones y intercambios con Ann H. Peters desde 2008 tienen una parte muy importante en el desarrollo de mis pensamientos. Además, discusiones con Hendrik Van Gijseghem desde 2010 y con Kevin J. Vaughn en 2011 y 2012, me ayudaron en varios puntos de mis investigaciones.

3 Traducción personal de: The Paracas site was the ritual and political center of a border region, meeting ground for communities.

4 Se usa el término de «tradición» según la definición propuesta por Peters (1997: 13).

5 Encontraron también un tercer sitio que llamaron Arena Blanca o Cabeza Larga, y que comparte numerosos rasgos culturales con Necrópolis (Tello y Mejía Xesspe 1979: 248-297).

${ }^{6} \mathrm{Al}$ excavar en Paracas, Tello y su equipo numeraron cada objeto y material arqueológico con un código único que empieza con 13/ seguido por dos o tres cifras (para el año de excavación de 1925) y en 12/ seguido de cuatro cifras (para los años 1927-1930).

7 Sería demasiado largo describir aquí todos los estilos y fases, así como sus distribuciones a lo largo de los valles de la costa sur y recomiendo el lector las numerosas publicaciones que existen y de las cuales he propuesto anteriormente un resumen (Tinteroff 2008: 52-80).

8 El tipo «Necrópolis engobado blanco» de Strong fue incluido posteriormente al estilo/fase Nasca 1 o al estilo/tradición Topará (Van Gijseghem 2006: 428, cuadro 2).

9 Traducción personal de «It is evident that, beginning in Paracas T-3 time and continuing into the Early Intermediate Period, there was great stylistic mixture at Cabeza Larga. The meaning of this 
conglomeration of styles is not clear, and will remain confusing until adequate archaeological units are isolated and described. The identification of the "Great Necropolis" vessels, and the full study of their associations with the various textile types, would surely throw some light on the relations between the Topará and Paracas-Nasca traditions in this crucial area."y de «Our understanding of cultural relations between Ica and the expended Topará area would be considerably enhanced if the monochrome ceramics accompanying some of the mummies were definitely identified as Paracas T-4, Nasca 1, as Jahuay 3 and Chongos, or as a blend of the two traditions.»

${ }^{10}$ En 2012, se publicó el Cuaderno $\mathrm{N}^{\circ} 9$ del Archivo Tello el cual trata de Necrópolis (Museo Nacional de Arqueológica y Antropología, Universidad Nacional Mayor de San Marcos) pero no he podido leer aún a ese libro.

${ }^{11}$ Ocho vasijas de Necrópolis fueron mandadas a Sevilla y nunca, según las informaciones que detenemos, regresaron al Perú. Son la olla 12/5542 (fardo 63), los cántaros 12/5669 (fardo 110), 12/6194 (fardo 237), 12/6889 (fardo 359) y 12/6998 (fardo 395), así que los platos 12/5695 (fardo 114), 12/6027 (fardo 197) y 12/6405 (fardo 293).

${ }^{12}$ Traducción personal de: «the elaboration of pan-regional social mechanisms to decrease warfare and increase collaboration (...)».

${ }^{13}$ Traducción personal de: «what is regarded as « chronological» can be an expression of the style of families or diffrent social groups».

${ }^{14}$ Traducción personal de: «les comportements humains tournés vers des pratiques religieuses peuvent se refléter dans la culture matérielle, indépendamment du caractère a priori utilitaire ou non utilitaire des objets».

${ }^{15}$ Unos autores (v.g. Peters 1997: 493; Reindel y Isla 2006: 250; Bachir y Llanos 2012: 214) mencionan unos artefactos ligados a la producción cerámica encontrados en varios sitios y contextos pero no mencionan estructuras o espacios reconocidos específicamente como ligados a la producción cerámica lo que es poco convincente ya que para identificar un sitio de producción cerámica, la «identificación de los rasgos, artefactos y espacios asociados con la manufactura cerámica es esencial para caracterizar correctamente una organización de la actividad de un sitio» (Sullivan III 1988: 32).Traducción personal de: «identification of the features, artifacts, and spaces associated with ceramic manufacture is essential to characterize properly a settlement's activity organization». ${ }^{16}$ Traducción personal de: «En classant les assemblages en fonction des chaînes opératoires à l'œuvre dans la fabrication des céramiques, ce sont les différentes entités socio-économiques productrices des céramiques composant les assemblages qui sont ainsi, dès l'abord, mises en évidence».

${ }_{17}$ Traducción personal de «segments temporels d'un seul individu».

${ }^{18}$ La metodología que uso parece acercarse a la usada por Wetter sobre la cerámica Paracas de Jauranga, valle de Palpa, tal como fue resumida por Reindel y Isla (2006: 253-256) y por Castro (et al. 2009: 150) pero no he podido leer aún a ese trabajo. Se acerca también a la de Livingstone Smith y Viseyrias (2010) sobre la cerámica Kabambian de Africa central.

${ }^{19}$ Lupa digital de base Dino-Lite, programa DinoCapture, versión 2.0, computadora Toshiba NB 505, Windows 7, propiedad del proyecto de Ann H. Peters y Elsa Tomasto-Cagigao.

${ }^{20}$ Mientras Peters no reconoce la presencia de un cuello en esas ollas, reconozco que esas ollas tienen un cuello aunque este es muy bajo.

${ }^{21}$ Esa vasija dejó problemas de identificación. Ya en nuestros diálogos con Ann H. Peters (2011-12) y con Maritza Perez Ponce (2012) no fue claro la identificación de esa vasija. Su forma muy pequeña y muy aplanada dejaba dudas en cuanto a su identificación como platillo. Observando una pasta idéntica y acabados idénticos en esa vasija y en la olla miniatura 12/5491, decidí juntar las dos vasijas y tratar de poner el dicho platillo sobre la boca de la olla. Entró perfectamente. 
${ }^{22}$ Lanning (1960: 410) identifica a las vasijas rosadas-violeta de la fase Chongos, indicando que se debe al control de la cocción (1960: 410). Según Peters (1997: 909), se usa un engobe delgado (selfslip) y el color rosado es un efecto de cocción. Necesito hacer análisis adicionales para determinar si se uso un engobe. Esperando ese momento, se clasifica como «engobe rosado-violeta» en mi ensayo.

${ }^{23}$ El numero 190 corresponde al numero original del fardo publicado bajo el numero 290 por Tello y Mejía Xesspe (1979: 384-422), ya que Tello cambio su número para que no sea llevado a la exposición de Sevilla (Aponte 2006: 11, 13; Peters 2007-12; Peters, comunicación personal 2013).

${ }^{24}$ Recordamos que la excavación de Necrópolis se hizo en 1927-1930 y que los trabajos arqueológicos de Tello y su equipo, el inventario del material y las notas de campo son, para esa época, de alta calidad aun si, por supuesto, no responden a las exigencias de hoy.

${ }^{25} \mathrm{La}$ existencia de tales conjuntos subraya la necesidad de encontrar y de poder estudiar a la colección más amplia posible de vasijas procedentes de Necrópolis.

\title{
REFERENCIAS
}

\author{
Albero, A. y J. Deyá \\ 2009 Individuo y cerámica en los rituales de entierro colectivo de Mallorca (2000-1400 a.C.), en: OrJIA (eds.), \\ Actas de las II Jornadas de Jóvenes en Investigación Arqueológica (Madrid, 6, 7 y 8 de mayo de 2009), 89-93, \\ Organización de Jóvenes en Investigación Arqueológica (OrJIA), Madrid.
}

Aponte, D.

2006 Presentación de los materiales del fardo funerario 290 de Wari Kayan, Paracas Necrópolis, Arqueológicas 27, 9-99.

Arnold, D. E.

1975 Ceramic ecology of the Ayacucho Basin, Peru: Implications for prehistory, Current Anthropology 16 (2), 183-205. https://doi.org/10.1086/201538

Bachir, A. y O. D. Llanos

2012 Arqueología e iconografía de los textiles Paracas descubiertos en Animas Altas, Ica, Perú, en: V. Solanilla (ed.), $V$ Jornadas Internacionales de Textiles Precolombinos 6, 211-230, Universidad Autónoma de Barcelona, Grup d'Estudis Precolombins, Barcelona.

Balfet, $\mathrm{H}$.

1953 Notes sur le façonnage des poteries préhistoriques, Bulletin de la Société Préhistorique Française 50 (4), 211-217. https://doi.org/10.3406/bspf.1953.3031

1966 La céramique comme document archéologique, Bulletin de la Société Préhistorique Française 63 (2), 279-310. https://doi.org/10.3406/bspf.1966.4071

Balfet, H., M.-F. Fauvet-Berthelot y S. Monzon

1983 Pour la normalisation de la description des poteries, Centre National de la Recherche Scientifique, Paris.

1988 Lexique plurilingue pour la description des poteries, Centre National de la Recherche Scientifique, Paris.

Bandy, M. S.

2004 Trade and social power in the southern Titicaca Basin Formative, Archaeological Papers of the American Anthropological Association, 14, 91-111. https://doi.org/10.1525/ap3a.2005.14.091

Bernier, H.

2009 La producción especializada de la cerámica domestica y ritual Mochica, Estudios Atacameños, 37, 157-178.https://doi.org/10.4067/S0718-10432009000100010

Castro, P. V., J. C. De la Torre y T. Escoriza

2007 Proyecto La Puntilla (Nasca, Ica, Perú). 2007. Prácticas sociales y producción de la vida social en los Horizontes del Formativo-Paracas de la Costa Sur del Perú; documento online: http://gl.www.mcu.es/patrimonio/ docs/MC/IPHE/Publicaciones/ExcavacionesExt07/16-Peru_La_Puntilla_Informes_Trabajos.pdf 


\section{Castro, P. V., J. C. De la Torre Zevallos y T. Escoriza}

2008 Proyecto La Puntilla (Nasca, Ica, Perú). Avances de las investigaciones 2008; documento online: <http:// www.mcu.es/patrimonio/docs/MC/IPHE/Publicaciones/IT/N3/puntilla_nasca_peru.pdf

Castro, P. V., J. C. De la Torre, T. Escoriza, M. C. Godoy, B. Lapi, I. Navarro y J. C. Zavala

2009 Trabajo, producción y cerámica. Sociología de la alfarería Paracas: Ocucaje y Tajo (costa sur de Perú), Estudios Atacameños, 37, 139-155. https://doi.org/10.4067/s0718-10432009000100009

Cauliez, J.

$20112900-1900$ av. n.è̀. Une méthodologie et un référentiel pour un millénaire de produits céramiques dans le Sud-Est de la France, Préhistoires Méditerranéennes, S, 1-126.

\section{Cauliez, J., G. Delaunay y V. Duplan}

2001 Nomenclature et méthode de description pour l'étude des céramiques de la fin du néolithique en France, Préhistoire Anthropologie Méditerranéennes, 10, 1-21.

Cervantes, G.

2010 El ritualizado proceso funerario y el rol de las vasijas en miniatura en Huaca Loro, valle de La Leche, tesis de licenciatura, Pontificia Universidad Católica del Perú, Lima.

\section{Chapdelaine, C., R. Mineau y S. Uceda}

1997 Estudio de los pigmentos de la cerámica ceremonial Moche con ayuda de un microscopio electrónico de barrido, Bulletin de l'Institut Français d'Etudes Andines, 26 (2), 229-245.

Chicoine, D.

2010 Elite Strategies and Ritual Settings in Coastal Peru during the $1^{\text {st }}$ Millenium B.C., en: R. E. Curtright, E. López-Hurtado y A. J. Martin (eds), Comparatives Perspectives on the Archaeology of Coastal South America, 191-212, Center for Comparative Archaeology, University of Pittsburgh, Pontificia Universidad Católica del Perú, Ministerio de Cultura de Ecuador, Pittsburg/Lima/Quito.

Cook, A. G.

1994 Investigaciones de reconocimiento arqueológico en la parte baja del valle de Ica, Informe Final 1988-1990.

\section{Delgado, M.}

2007 Investigaciones arqueológicas en Villa El Salvador: Secuencia cerámica en contextos funerarios, tesis de licenciatura, Pontificia Universidad Católica del Perú, Lima.

\section{DeLeonardis, L.}

1997 Paracas settlement in Callango, Lower Ica Valley, first millenium B.C., Peru, tesis de doctorado, The Catholic University of America, Ann Arbor.

Demoule, J.-P.

1994 La céramique comme marqueur social: variabilité spatiale et chronologique, en: D. Binder y J. Courtin (eds), Terre cuite et société. La céramique, document technique économique et culturel, Actes des $14 e$ Rencontres Internationales d'Archéologie et d'Histoire d'antibes, 21, 22, 23 octobre 1993, 473-492, Centre de Recherches Archéologiques.

Dietz, M. J.

2009 Diet, subsistence and health: A bioarchaeological analysis of Chongos, Peru, tesis de doctorado, University of Missouri, Columbia.

Druc, I. C.

1996 De la etnografía hacia la arqueología: aportes de entrevistas con ceramistas de Ancash (Perú) para la caracterización de la cerámica prehispánica, Bulletin de l'Institut Français d'Etudes Andines, 25 (1), 17-41.

Engel, F. A.

1992 Un desierto en tiempos prehispánicos: río Pisco, Paracas, río Ica, Didi de Arteta S.A, Lima.

Fehren-Schmitz, L.

2010 Dinámica poblacional y desarrollo cultural prehispánicos en la costa sur del Perú: lo que revelan los análisis de ADN antiguo, Boletín de Arqueología PUCP 14, 329-353. 


\section{Feinman, G. M., S. Upham y K. G. Lightfoot}

1981 The production step measure: An ordinal index of labor input in ceramic manufacture, American Antiquity, 46 (4), 871-884. https://doi.org/10.2307/280113

Gerdau-Radonic, K.

2007 Les tombes collectives de Tablada de Lurin (vallée de Lurin, Pérou; I ${ }^{\text {er }}-\mathrm{III}^{\mathrm{e}}$ s. ap. J.C.), tesis de doctorado, Université Bordeaux I, Pontificia Universidad Católica del Perú, Bordeaux/Lima.

\section{Ghezzi, I.}

2011 El análisis composicional en el estudio de la producción y distribución de la cerámica prehispánica, Bulletin de l'Institut Français d'Etudes Andines 40 (1), 1-29.

\section{Glascock, M. D., H. Neff y K. J. Vaughn}

2004 Instrumental neutron activation analysis and multivariate statistics for pottery provenance, Hyperfine interactions, 154, 95-105. https://doi.org/10.1023/B:HYPE.0000032025.37390.41

\section{González, M. I., M. M. Frére y R. Frontini}

2012 Formas de ollas de cerámica pampeana y consumo de alimentos, en: M. P. Babot, M. Marschoff y F. Pazzarelli (eds.), Las manos en la masa. Arqueologias, Antropologías e Historia de la alimentación en Suramérica, 405-424, Córdoba.

Hally, D. J.

1986 The identification of vessel function: A case study from Northwest Georgia, American Antiquity 51 (2), 267-295. https://doi.org/10.2307/279940

Hecht, $\mathrm{N}$.

2009 Of layers and sherds: A context-based relative chronology of the Nasca Style pottery from Palpa, en: M. Reindel y G. A. Wagner (eds.), New technologies for archaeology. multidisciplinary investigations in Palpa and Nasca, Peru, 207-230, Natural Science in Archaeology, Springer-Verlag Berlin Heidelberg. https:// doi.org/10.1007/978-3-540-87438-6_13

Isbell, W. H.

1997 Mummies and mortuary monuments, a Postprocessual prehistory of central Andean social organization, University of Texas, Austin.

Isla, J., Reindel, M. y J. C. De La Torre

2003 Jauranga: un sitio Paracas en el valle de Palpa, costa sur del Perú, Beiträge zur Allgemeinen und Vergleichenden Archäologie 23, 227-274.

Johnson, G. A.

1977 Aspects of regional analysis in archaeology, Annual Review of Anthropology 6, 479-508. https://doi. org/10.1146/annurev.an.06.100177.002403

\section{Kantner, J. y K. J. Vaughn}

2012 Pilgrimage as costly signal: Religiously motivated cooperation in Chaco and Nasca, Journal of Anthropological Archaeology 31, 66-82. https://doi.org/10.1016/j.jaa.2011.10.003

Kubler, G.

1970 Period, style and meaning in ancient American Art, New Literary History 1 (2), 127-144. https://doi. org/10.2307/468624

Lanning, E. P.

1960 Chronological and cultural relationships of early pottery in ancient Peru, tesis de doctorado, Department of Anthropology, University of California, Berkeley.

Lau, G. F.

2008 Ancestor images in the Andes, en: H. Silverman y W. Isbell (eds), Handbook of South American Archaeology, 1025-1044, Springer, New York. https://doi.org/10.1007/978-0-387-74907-5_51

Levy, J. E.

1981 Ritual and social stratification in prehistoric societies: An example from Bronze Age Denmark, History of Religions 21 (2), 172-188. https://doi.org/10.1086/462894 
Livingstone, A. y A. Viseyrias

2010 Shaping Kabambian pottery: Identification and definition of technical features, The Open Anthropology Journal 3, 124-141. https://doi.org/10.2174/1874912701003010124

Llanos, O. D.

2008 Paralelismo e interacción paracas nazca y la emergencia del Estado en la cuenca del Río Grande de Nazca, en: A H. Peters y H. Van Gijseghem (org.), $73^{\text {rd }}$ Annual Meeting de la Society for American Archaeology, 27 de marzo de 2008, documento online: <http://hal.archives-ouvertes.fr/halshs-00576963/>

Massey, S. A.

1986 Sociopolitical change in the Upper Ica Valley, B.C. 400 to 400 A.D.: Regional states on the south coast of Peru, tesis de Doctorado, University of California, Los Angeles.

Menzel, D., J. H. Rowe y L. E. Dawson

1964 The Paracas Pottery of Ica: A Study in Style and Time, University of California Press, Berkeley.

Museo Nacional de Antropología, Arqueología e Historia del Perú (MNAAHP)

Libro de inventario, volumen 9; documento no publicado.

Museo Nacional de Antropología, Arqueología e Historia del Perú (MNAAHP)

Libro de inventario; volumen 10; documento no publicado.

Nicklin, K.

1979 The location of pottery manufacture, Man, New Series 14 (3), 436-458. https://doi.org/10.2307/2801868

Orefici, G. y A. Drusini

2003 Nasca: Hipótesis y evidencias de su desarrollo cultural, Centro Italiano Studi e Ricerche Archeologiche Precolombiane, Brescia.

Paul, A.

1990 Paracas ritual attire: Symbols of authority in ancient Peru, University of Oklahoma Press, Norman/London.

1991 Paracas Necrópolis Bundle 89, en: A. Paul (ed.), Paracas art and architecture: Object and context in south coastal Peru, 172-221, University of Iowa Press, Iowa City.

Peters, A. H.

1997 Paracas, Topará and early Nasca: Ethnicity and society on the south central Andean Coast, tesis de Doctorado, Cornell University, Ithaca.

2000 Funerary regalia and institutions of leadership in Paracas and Topará, Chungara, Revista de Antropología Chilena 32 (2), 245-252. https://doi.org/10.4067/S0717-73562000000200016

2005- Paracas Necrópolis: Salvaging Contextual Relationship, Dumbarton Oaks Project; documento online:

2006 <http://www.doaks.org/research/pre-columbian/pre-columbian-project-grant-reports-1/doaks-pcoproject-grant-report-2005>

2007 Re-contextualization of collections: Collaboration and exchange among museums; documento online: $<$ http://vm1.lightlink.com/-ancar119/wp-content/uploads/2009/10/Peters-RestoringContext07.pdf>

2007- Base de datos del Proyecto «Practicas en vida, presencia después de la muerte: lo estilístico y lo material

2012 en la Necrópolis de Paracas»; documento no publicado.

2008 Practices in life, presence after death: Style and substance at the Paracas Necrópolis; documento no publicado.

Peters, A. H. y H. Van Gijseghem (org.)

2008 Interaction, innovation and social change: The Paracas-Nasca transition, Symposium, en: $73^{\text {rd }}$ Annual Meeting of the Society for American Archaeology, Marzo 26-30, 2008, Vancouver, Canada, ponencias no publicadas.

Peters, A. H., E. Tomasto-Cagigao, S. Arce, C. Del Aguila, H. Van Gijseghem y J. Isla (org.)

2012 Symposium: Paracas-Nazca. A «transitional» period of the Late Formative, South Coast of the Central Andes, August 9-11, 2012, Ica, Perú; ponencias no publicadas.

Reindel, M. y J. Isla

2006 Evidencias de culturas tempranas en los valles de Palpa, costa sur del Perú, Boletín de Arqueología PUCP $10,237-283$. 
Roux, V. y M.-A Courty

2005 Identifying social entities at a macro-regional level: chalcolithic ceramics of South Levant as a case study, en: D. Bosquet, A. Livingstone-Smith y R. Martineau (eds.), Pottery manufacturing processes: Reconstruction and interpretation, 201-214, Archaeopress, BAR International Series, Oxford.

Roux, V. y M.-A Courty

2007 Analyse techno-pétrographique céramique et interprétation fonctionnelle des sites: un exemple d'application dans le Levant Sud chalcolithique, en: A. Bain, J. Chabot y M. Moussette (eds.), La mesure du passé: contributions à la recherche en archéométrie (2000-2006), 153-168, Archaeopress, CELAT, Université Laval, BAR International Series 1700, Série archéométrie numéro 5, Oxford/Québec.

2010 Lecture anthropologique des assemblages céramiques. Fondement et mise en oeuvre de l'analyse technologique, Les nouvelles de l'archéologie 119, 4-9. https://doi.org/10.4000/nda.957

Rowe, J. H.

1958 La seriación cronológica de la cerámica de Paracas elaborada por Lawrence E. Dawson, Revista del Museo Regional de Ica 9 (10), 9-21.

\section{Rozenberg, C. y M. Picon}

1990 Circulation, échange et production de poteries dans les Andes centrales au deuxième millénaire av. J.C., Bulletin de l'Institut Français d'Etudes Andines 19 (1), 1-14.

Ruby, B. J. y Ch. Shriner

2005 Ceramic vessel compositions and style as evidence of the local and nonlocal social affiliations of ritual participants at the Mann Site, Indiana, en: C. Carr y D. T. Case (eds.), Gathering Hopewell. Society, ritual and ritual interaction, 553-572, Kluwer Academic/Plenum Publishers/Springer US, New York. https:// doi.org/10.1007/0-387-27327-1_15

Santley, R. S., P. J. Arnold III y C. A. Pool

1989 The Ceramics production system at Matacapan, Veracruz, Mexico, Journal of Field Archaeology 16 (1): 107-132. https://doi.org/10.1179/jfa.1989.16.1.107

\section{Schneider, S. E., E. J. Schuetz y R. E. Ahlrichs}

2012 Intraregional social interaction in late prehistory: Paste compositional analysis of Oneota pottery vessels in the Lake Koshkonong Region, Field Notes: A Journal of Collegiate Anthropology 4 (1), 192-215.

Shady, R. y A. Ruiz

1979 Evidence for interregional relationships during the Middle Horizon on the North-Central Coast of Peru, American Antiquity 44 (4), 676-684. https://doi.org/10.2307/279106

Shepard, A. O.

1985 Ceramics for the archaeologist, Carnegie Institution of Washington, Publication 609, Washington, D.C.

Silva S., J. E.

1998 Una aproximación al período formativo en el valle del Chillon, Boletín de Arqueología PUCP 2, 251-268.

Silverman, $\mathrm{H}$.

2002 Nasca settlement and society on the hundredth anniversary of Uhle's discovery of the Nasca Style, en: W. H. Isbell y H. Silverman (eds.), Andean archaeology: variations in sociopolitical organization, 121-158, Kluwer Academic/Plenum Publishers, New York. https://doi.org/10.1007/978-1-4615-0639-3_5

Sinopoli, C. M.

1991 Approaches to archaeological ceramics, Plenum, New York. https://doi.org/10.1007/978-1-4757-9274-4

Strong, W. D.

1957 Paracas, Nazca and Tiahuanacoid Cultural Relationships in South Coastal Peru, Memoirs of the Society for American Archaeology, 13, 1-48.

Stanish, C. y H. Tantaleán

2012 The Paracas cultures of Southern Peru, course syllabus, July 1-August 11, 2012; documento online: $<$ http://www.ifrglobal.org/programs/current/peru-chincha> 
Sullivan III, A. P.

1988 Prehistoric southwestern ceramic manufacture: The limitations of current evidence, American Antiquity 53 (1): 23-35. https://doi.org/10.2307/281152

Tello, J. C.

1929 Antiguo Perú. Primera época, Comisión organizadora del Segundo Congreso Sudamericano de Turismo, Lima.

Tello J. C. y T. Mejía Xesspe

1959 Paracas. Primera parte. Publicación del Proyecto 86 del programa 1941-42 de the Institute of Andean Research, Institute of Andean Research, New York.

1979 Paracas. Segunda parte. Publicación antropológica del Archivo «Julio C. Tello», Institute of Andean Research, Universidad Nacional Mayor de San Marcos, Dirección Universitaria de Biblioteca y Publicaciones, New York/Lima.

Tinteroff, V.

2005 Informe de investigación sobre cerámicas en el Museo Nacional de Arqueología, Antropología e Historia del Perú, Lima, Perú, informe no publicado online: <http://independent.academia.edu/VanessaTinteroff>

2008 De Paracas à Nasca sur la côte sud du Pérou : archéologie d'une mutation culturelle, tesis de doctorado, Université Paris Sorbonne (Paris IV), Paris.

2009 Paysage et diversification culturelle: le cas de la côte sud du Pérou à l'époque Paracas-Nasca (200 av. J.C. - 100 apr. J.C.), en: C. Lemaire y G. Hourdin (org.), Journée d'étude "Paysage(s)» 6 novembre 2009, Association Toulousaine pour la Recherche Interdisciplinaire sur les Amériques (ATRIA), Toulouse, acta online: <http://atria.phpnet.org/association-atria/wp-content/uploads/2012/01/Paysages_Tinteroff_ Communication.pdf>

2011a Informe de investigación (año 2010) al Museo Nacional de Arqueología, Antropología e Historia del Perú, Lima, Perú, informe no publicado online: <http://independent.academia.edu/VanessaTinteroff>

2011 b Informe de investigación. Inventariar y contextualizar las cerámicas de la península de Paracas encontradas por Julio César Tello y Toribio Mejía Xesspe (1925-1930) al Museo Nacional de Arqueología, Antropología e Historia del Perú, Lima, Perú, informe no publicado online: <http://independent.academia.edu/VanessaTinteroff>

2012a Informe de investigación: las cerámicas de la «transición» Paracas-Nasca de la colección Aldo Rubini Drago del Museo Regional de Ica al Museo Regional de Ica, Ica, Perú, informe no publicado.

2012b Re-Descubrir a las cerámicas de Necrópolis de Wari Kayan, península de Paracas: inventariar, clasificar y contextualizar, en: E. Tomasto-Cagigao y A. H. Peters (directoras), Informe del Proyecto «Practicas en vida, presencia después de la muerte: lo estilistico y lo material en la Necrópolis de Paracas», informe no publicado.

Tschopik, H. Jr.

1950 An Andean ceramic tradition in historical perspective, American Antiquity 15 (3), 196-218. https://doi. org/10.2307/276763

\section{Cuadernos de campo (1925-1930), Instituto Riva-Agüero, Pontificia Universidad Católica del Perú, Lima}

Tmx-625 - Historia de la excavación de las Momias N90 a 265 de las Grandes Necrópolis y de las Cavernas VI y VII de Cerro Colorado, Paracas, versión transcripta por Alberto Ayarza Uyaco, 2007, documento no publicado.

Tmx-626 - Descripción de las Cavernas XXVI, XXVII, XXX y XXXII de Cerro Colorado e Historia de las Momias $N^{\circ} 1$ a 101 del Cementerio A en las faldas de Cerro Colorado, Paracas, versión transcripta por Alberto Ayarza Uyaco, 2006; documento no publicado.

Tmx-635 - Historia de la excavación de las Momias No310 a 350 (1927), N³51 a 451 (1928), N452 a 465 (1929) de Cabeza Larga y Wari Kayan, Paracas. Exploración a Huacho-Paramonga y Cieneguilla (1928), versión transcripta por Alberto Ayarza Uyaco, 2007; documento no publicado.

Tmx-636 - Cuaderno de Informe de Antonio Hurtado sobre los trabajos realizados en Wari Kayan, Paracas (Cateos $N^{\circ} 101$ a 324), versión transcripta por Alberto Ayarza Uyaco, 2008; documento no publicado.

Unkel, I., B. Kromer, M., Reindel, L. Wacker y G. Wagner

2007 A chronology of the pre-Columbian Paracas and Nasca cultures in south Peru based on AMS ${ }^{14} \mathrm{C}$ Dating, Radiocarbon 49 (2), 551-564. https://doi.org/10.1017/S0033822200042466 
Valdez, L. M.

1988 Patrones de subsistencias Nasca: Una perspectiva desde Kawachi y Tambo Viejo, tesis de licenciatura, Universidad Nacional de San Cristobal de Huamanga, Ayacucho.

Van Gijseghem, $\mathrm{H}$.

2004 Migration, agency and social change on a prehistoric frontier: The Paracas-Nasca transition in the southern Nasca Drainage, tesis de doctorado, University of California, Santa Barbara.

2006 A frontier perspective on Paracas Society and Nasca ethnogenesis, Latin American Antiquity, 17 (4), 419-444. https://doi.org/10.2307/25063066

Van Gijseghem, H. y K. J. Vaughn

2008 Regional integration and the built environment in middle-range societies: Paracas and early Nasca houses and communities, Journal of Anthropological Archaeology 27, 111-130. https://doi.org/10.1016/j. jaa.2007.11.002

Van Gijseghem, H., K. J. Vaughn, V. H. Whalen, M. Linares y J. Olano

2013 Economic, social, and ritual aspects of copper mining in ancient Peru: An upper Ica Valley case study, en: N. Tripcevich y K. J. Vaughn (eds.), Mining and quarrying in the ancient Andes. Sociopolitical, economic, and symbolic dimensions, 275-298, Springer, New York. https://doi.org/10.1007/978-1-4614-5200-3_13

Vaughn, K. J.

2005 Crafts and the materialization of chiefly power, en: K. J. Vaughn, Ch. Conlee y D. Ogburn (eds.), The foundations of power in the pre-Hispanic Andes, 113-130, Archaeological Papers of the American Anthropological Association, 14, Washington, D.C. https://doi.org/10.1525/ap3a.2004.14.113

Vaughn, K. J., Ch. A. Conlee, H. Neff y K. Schreiber

2006 Ceramic production in ancient Nasca: provenance analysis of pottery from the Early Nasca and Tiza cultures through INAA, Journal of Archaeological Science 33, 681-689. https://doi.org/10.1016/j. jas.2005.10.002

Vaughn, K. J., L. Dussubieux y P. R. Williams

2011 A pilot compositional analysis of Nasca ceramics from the Kroeber collection, Journal of Archaeological Science 38, 3560-3567. https://doi.org/10.1016/j.jas.2011.08.025

Vaughn, K. J. y M. Linares

20063,000 years of occupation in Upper Valley Nasca: Escavations at Upanca, Latin American Antiquity 17 (4), 595-612. https://doi.org/10.2307/25063074

Vaughn, K. J. y H. Neff

2000 Moving beyond Iconography: Neutron analysis of ceramics from Marcaya, Peru, an Early Nasca domestic site, Journal of Field Archaeology 27 (1), 75-90. https://doi.org/10.1179/jfa.2000.27.1.75

2004 Tracing the clay source of Nasca polychrome pottery: results from a preliminary raw material survey, Journal of Archaeological Science 31, 1577-1586. https://doi.org/10.1016/j.jas.2004.03.021

Vaughn, K. J. y H. Van Gijseghem

2007 A compositional perspective on the origin of the "Nasca cult» at Cahuachi, Journal of Archaeological Science 34, 814-822. https://doi.org/10.1016/j.jas.2006.08.008

Vidal, A., J. García y D. Albero

2009 ¿Hay alguien ahí? Buscando a las personas tras la cerámica arqueológica, en: OrJIA (eds.), Actas de las II Jornadas de Jóvenes en Investigación Arqueológica (Madrid, 6, 7 y 8 de mayo de 2009) 11-12, Organización de Jóvenes en Investigación Arqueológica (OrJIA), Madrid. 